\title{
Sweetening the Pill: A Theory of Waiting To Merge*
}

\author{
Eileen Fumagalli \\ Norwegian Competition Authority \\ eifu@kt.no
}

\author{
Tore Nilssen \\ University of Oslo \\ tore.nilssen@econ.uio.no
}

May 20, 2019

\begin{abstract}
Merger policy is a permission-granting activity by government in which there may be disincentives to seek permission because of the benefit from having other firms merge. We set up a sequential merger game with endogenized antitrust policy to study one aspect of these disincentives. In particular, we delineate a pill-sweetening motive for waiting to merge: a small firm may choose to let other bigger firms move first, in order to get more mergers approved by government. We report the prevalence of pill sweetening to occur in equilibrium and find it to hinge on efficiency gains from a merger, differently-sized firms, firms' production technology, the presence of an antitrust authority, the alignment of interests between antitrust authorities and firms, and the number of firms in the industry.

JEL classification: L11; L13; L41; G34.
\end{abstract}

\footnotetext{
${ }^{*}$ We are grateful for helpful comments from an anonymous referee. In addition, we are grateful for comments from, and discussions with, Jonas Björnerstedt, Sven-Olof Fridolfsson, Kai-Uwe Kühn, Volker Nocke, Lars Persson, Åsa Rosén, Christian Schultz, Lars Sørgard, Frode Steen, Helder Vasconcelos, and Jon Vislie, as well as participants at seminars at BI Norwegian Business School, the Universities of Bergen and Oslo, the Research Institute of Industrial Economics (Stockholm), and the Norwegian School of Economics, and at EARIE in Valencia, the Norwegian Economists Meeting in Oslo, IIOC in Arlington, the BECCLE Conference in Bergen, NORIO in Reykjavik, and CRESSE at Rhodes. We have received able research assistance from Esther Ann Bøler, Ella Getz Wold, Eirik Brandsås, Dana Øye, and Anne Killi. Part of Fumagalli's research was carried out while she was affiliated with IGIER and IEFE, both at Bocconi University. Nilssen thanks IGIER and IEFE for their hospitality. During this research, Nilssen was associated with the ESOP Centre at the University of Oslo; ESOP received support from the Research Council of Norway through its Centres of Excellence funding scheme, project number 179552. Views expressed in this article are not necessarily in line with the views of the Norwegian Competition Authority.
} 


\section{Introduction}

Many government activities take the shape of granting permissions to firms. The typical picture is that firms rush to get such permissions, because the number of permissions are limited, and because being without one puts you at a disadvantage in subsequent rivalry. Merger policy is a permission-granting activity that is special, since firms without a permission, i.e., the non-merging units, often benefit from other firms' merging. Thus, it is not clear whether it pays for firms to rush to merge. In fact, there may be an incentive to hold back on one's own merger plans because of the positive externality exerted by mergers on non-merging firms.

In this paper, we point to a novel aspect of this incentive to not rush to merge: letting other firms merge first makes it sometimes easier to get one's own merger plans through the antitrust authority - it sweetens the pill and makes it easier for the antitrust authority to swallow it.

In order to discuss the issue, we construct a model of sequential mergers with two key ingredients. First, the antitrust authority takes active part. In particular, while it does not pick merger proposals, no proposal is carried out without the authority's approval. Secondly, firms differ in terms of size and efficiency. The implication is that, in situations where the antitrust authority does not want to approve all merger proposals put before it, the sequence of merger proposals matters for the outcome of the process. And firms may want to abstain from an early merger proposal if that proposal would mean that this merger, but no further mergers, would be approved. With our model, we show that this can happen in equilibrium, with a firm abstaining from a merger today in order to sweeten the pill and persuade the antitrust authority to accept a more concentrated industry in the future than it otherwise would.

Firms may abstain from merger in order to free ride on other firms' mergers. This possibility creates a disincentive for merger. Such free-riding on other firms' merger is particularly lucrative when the antitrust authority would be interested in allowing some mergers, but not too many. ${ }^{1}$

A merger that raises the equilibrium price in the industry benefits also nonmerging firms. If the antitrust authority would allow only a single merger, then a small firm may be better off passing up on its own opportunity to merge and be on the outside of a big entity with a considerable price rise, than merging itself and being on the inside of a smaller merger with a meager price rise. Thus, the firm obtains increased concentration in the industry by not merging itself. This is the free-riding motive for not merging.

If, alternatively, the antitrust authority would anyhow allow more than one mergers to take place, then the firm might improve its bargaining position visà-vis its merging partners by arriving late at the bargaining table. The reason for this is essentially the free-riding motive just discussed: a firm on the outside

\footnotetext{
${ }^{1}$ This disincentive for merger has been discussed extensively in previous work - notably by Stigler (1950) and Salant, et al. (1983) - but it has not previously been spelled out in a setting where antitrust policy is endogenized. The literature makes at most the simple assumption that only one merger can take place, because of some unmodelled antitrust authority.
} 
of a big merged unit has a large inside option and therefore a strong bargaining position when entering negotiations to join the big unit. It would thus pay for a firm to pass up on an early opportunity to merge in order to strengthen its bargaining position before eventually merging later. This is the bargainingpower motive for not merging. ${ }^{2}$

But there is a third possibility, and this is the main focus here. It arises, as indicated already above, in intermediate cases - where the antitrust authority may or may not allow several mergers, and where a firm, by postponing its own merger proposal, may get more mergers through the antitrust authority than it would if it itself would merge immediately. As our analysis shows, this happens in cases where the firm is small relative to the other firms in the industry. To see how this may happen, note that, if allowing a single merger only, the antitrust authority will in many cases want that single merger to be small, i.e., to involve the small firm. This is particularly so if there has been a big merger in the past, i.e., one not involving the small firm. In such cases, the authority may approve a second merger if the first merger were big but not if it were small. In such intermediate cases, it may pay for a small firm to pass on an opportunity to merge early in order to entice the antitrust autority to allow an extra merger to take place. We call this the pill-sweetening motive for not merging early.

Our model features a set of firms as well as an antitrust authority and has two periods. In the first period, the firms and the antitrust authority play a sequential merger game, to be described in more detail shortly. In the second period, the firms left after any consolidations in the first period compete in quantities in a product market. With a focus on a firm's incentives to pass up on an opportunity to merge, we model one firm as being of a different size at the outset than the other firms in the industry and discuss whether this particular firm has incentives to abstain from a chance to be part in an early merger. ${ }^{3}$ After a merger proposal, the antitrust authority makes a decision whether or not to approve the merger. The only mergers that are carried out are those that pass the scrutiny of the antitrust authority. The agency is assumed to be forward-looking, but unable to commit to any future action. ${ }^{4}$

In order to get a picture of the merger game played in the first period, consider an industry consisting of three firms. If the first firm, of a different size than the other two, decides not to take part in a merger (or if it does but the merger is not approved), then the two other firms decide whether to

\footnotetext{
${ }^{2}$ See, e.g., Bloch (1996), Fridolfsson and Stennek (2005a), and Rodrigues (2014) for analyses where this is played out in various ways.

${ }^{3}$ In Section 5 we discuss the alternative, to let one of the other firms, equal sized by assumption, move first and find this to be less interesting.

${ }^{4}$ The notion that the antitrust authority is forward-looking is common in the literature; see, e.g., Mermelstein, et al. (2018). Moreover, Hovenkamp (2019) discusses how merger policy can and should look ahead and accommodate the effects a merger will have on the future of the industry involved. While he does not mention future horizontal mergers, his arguments might be applicable also to such cases. Still, it appear to be a widely held view that it is illegal, in both the EU and the US, for an antitrust authority to base current merger decisions on what they will imply for future merger decisions. The implications for our analysis of the alternative position, that it is impossible for the antitrust authority to be forward-looking when deciding on merger proposals, are discussed in Section 5.
} 
merge with each other. If they do, and their proposal is approved, then the first firm reconsiders whether to take part in a merger, since now the situation has changed from the previous stage when a decision not to merge was made. This feature of our model allows the first firm to merge eventually, even when the game starts out with a decision by that firm not to merge.

There are two things worth noting at this point. First, we only consider pairwise mergers. This is in line with earlier literature, such as Macho-Stadler, et al. (2006), and also fits the observation that most mergers are in fact pairwise. Moreover, allowing a proposal to merge immediately to monopoly would not affect results. Secondly, a decision to merge is made jointly by the two firms involved. For ease of exposition, we model this formally, though, as one firm finding a merging partner and deciding whether to merge with it, with an equal sharing of the gains from merger. This equal sharing of gains means that firm $i$ does not want to merge with firm $j$ if and only if firm $j$ does not want to merge with firm $i$.

In our analysis, we find five aspects of our model that are crucial for the occurrence of pill sweetening. The first such aspect is the presence of the antitrust authority, as already noted. Clearly, there cannot be a pill-sweetening motive for not merging without the antitrust authority around. It is only when it is there and takes an active part that the number of mergers to be approved is endogenous, so that firms may have an incentive to set it up to accept more merging.

Although the pill-sweetening motive is our prime interest, we note that also the free-riding motive hinges on the antitrust authority's presence, since this motive comes about from its allowing only a limited number of mergers. The bargaining-power motive, on the other hand, shows up even when the antitrust authority disappears; in fact, the interesting result is rather of the opposite flavor: even with the antitrust authority present, cases exist where multiple mergers take place while still it pays for the first firm to delay its own entry into the sequence of mergers.

Secondly, again as already noted above, asymmetry among firms is crucial in producing pill sweetening: with all firms of equal size, there is no way the number of approved mergers can be affected by the sequence they arrive in. We model firm asymmetry in the simplest way possible: we let one firm differ in size from the others, which on the other hand are of equal size. ${ }^{5}$

Thirdly, there must be some efficiency gains associated with a merger. Without such gains, the antitrust authority would not have reason to allow any

\footnotetext{
${ }^{5}$ The importance of firm asymmetry for outcomes of merger games is also stressed by others. Tombak (2002) finds that introducing firm asymmetry into the Kamien-Zang (1993) analysis increases the scope for merger to monopoly. Qiu and Zhou (2007) report that firm heterogeneity is crucial for the creation of a merger wave in their model. Fridolfsson (2007) finds that, with asymmetry, big firms will merge - a result resembling ours on the free-riding motive. Cunha and Vasconcelos (2018) discuss sequential mergers in an industry with both Stackelberg leaders and followers. Barros (1998) uses a different cost structure than ours, and thus a different kind of firm asymmetry, that we discuss in more detail in Section 5 below. Gowrisankaran (1999), in his analysis, simply lets bigger firms merge first, an assumption that fits well with our prediction that indeed big firms merge before small ones.
} 
merger, and we would not be able to see the interplay between what the agency would allow and what the firm would like to see happen that we have described above. Also, efficiency gains from merging creates a scope for a rebalancing of the industry through a second merger to enhance welfare. ${ }^{6}$ And the presence of efficiency gains creates an incentive for firms to merge in the first place. Like in Perry and Porter (1985), there is an input factor in total fixed supply and available only inside the industry, making a merger reduce costs for the firms taking part in it. The crucial industry-specific factor can be thought of as human capital: knowledge about doing business in this industry is available inside the industry only, and the more you have of it, the more efficiently you can run your firm.

Fourthly, firms' production technology must not be too sensitive to scale. If it is, so that an increase in a firm's production gets swamped by increases in costs, then the antitrust authority's motivation for accepting mergers vanishes, and the scope for pill sweetening correspondingly disappears.

Finally, there must be sufficient alignment between the firm's interests and those of the antitrust authority. In our model, the antitrust authority is more interested in allowing mergers the smaller the market, since a small market indicates there may be too many firms in the industry. But if the antitrust authority's aim is to maximize consumer surplus, then mergers will only be allowed for very small markets. In particular, a firm's incentive to pass up on an initial opportunity to take part in a merger would in such a case only show up for market sizes for which the consumer-surplus maximizing antitrust authority does not allow any mergers. With more weight put on firms' profits in the antitrust authority's objective function, the scope for allowing mergers increases, and there is eventually an overlap between combinations of market size and firm asymmetry for which on the one hand the antitrust authority is interested in allowing one or more mergers and on the other hand firms are interested in waiting to merge. Note that also the free-riding motive to waiting to merge disappears as the antitrust authority's preferences get close to the consumer welfare standard, since then only mergers that lower the price are allowed, which is not much to free ride on. It follows that also the bargainingpower motive disappears in these circumstances. ${ }^{7}$

\footnotetext{
${ }^{6}$ See, e.g., Farrell and Shapiro (1990, in particular Sec. III.D) on how the external effect of a merger increases in the concentration of the non-merging firms in the presence of efficiency gains from a merger. This implies that a merger is more benign, in terms of its external effect, if other firms have merged before it.

${ }^{7}$ Current policy in both the EU and the US is strongly consumer biased; see, e.g., Whinston (2007). Outside the EU and the US, the picture is mixed. Ross and Winter (2005) argue that Canadian merger policy is close to the total welfare standard. International Competition Network (2011) also lists Australia and New Zealand, as well as some emerging economies, among jurisdictions close to a total welfare standard. It should be noted that Ashenfelter, et al. (2014) and Kwoka (2015) find that actual US merger policy has been closer to the total welfare standard than the statutes indicate. And scholars like Carlton (2007), Blair and Sokol (2012), and Kaplow (2012) argue in favor of moving US antitrust law towards a total welfare standard. Moreover, Glick (2018) and other so-called neo-Brandeisian scholars argue that the consumer-versus-total welfare discussion misses the point and that more emphasis should be put on market structure. As discussed in the text, the scope for pill sweetening is greatest in
} 
In addition to these five issues, also the number of firms in the industry affects the prevalence of pill sweetening to occur in equilibrium. In our main analysis, there are three firms in the industry. While the three-firm case makes for a transparent analysis, the scope for pill sweetening is there limited, since it can only happen when the industry ends up in complete monopoly. In cases of more than three firms, on the other hand, pill sweetening would occur also without the industry ending in a state of monopoly. This is discussed in Section 4 , where we present details of the four-firm case, which shows the prevalence of cases where firms abstain from an early merger in order to induce the antitrust authority to allow mergers to duopoly. As is evident from that discussion, an increase from three to four firms means a strong increase in the scope for pill sweetening to occur in equilibrium.

Our analysis has an interesting empirical implication: Big firms tend to merge before small firms. We find, in particular, that the pill-sweetening motive for waiting to merge occurs only for firms of size below the industry average. This happens because big firms merging creates an imbalance that can be used by small firms in order to entice the antitrust authority to allow also them to merge afterwards. This empirical implication is best spelled out in cases of more than three firms. Again, see Section 4 on the four-firm case, where a small firm, instead of merging now, may choose to take part in a merger later on with another non-merged firm, thus restoring some of the balance lost after a first, big-firm merger - so that we have a sequence of a big merger followed by a smaller one.

This prediction would, of course, not be possible to get out of a study of equal-sized firms. Do big firms merge before small firms also in real life? For the purpose of answering this, it would be nice to collect data on industries where multiple mergers have been observed, particular in jurisdictions that are close to the total welfare standard. Empirical studies of this issue would anyhow be hampered by our inability to observe any firms' decisions not to merge. We thus seem to have to resort to case studies. One such study is by Nilssen (1997), discussing two Norwegian insurance mergers that both were let through, the first bigger than the second. Anticipating the present analysis, Nilssen suggests that society would have been better off if the two mergers had been proposed in the reverse order.

The present model belongs to a growing literature on endogenous mergers. According to Horn and Persson (2001a), a model of endogenous merger is one where more than one merger constellation is possible, and they delineate three distinct approaches to such models. One of them is atemporal, based on cooperative game theory, and exemplified by Horn and Persson themselves. The second approach is pioneered by Kamien and Zang (1990), with the owner of each firm, in each round of the merger game, setting a bid price for each of the other firms and an ask price for her own firm. Finally, there is the bargaining approach suggested by Ray and Vohra (1999), with bargaining taking place according to a fixed protocol. Our model contains such a fixed protocol, although

countries close to the total welfare standard. 
a very simple one. ${ }^{8}$ We differ from Ray and Vohra, however, in letting merged units stay in the game so that they can take part in further mergers, whereas their merged units leave the game. Also Macho-Stadler, et al. (2006) let merged units stay in the game. Unlike us, however, they have a random protocol. With asymmetric firms, such a random protocol would not be appropriate. While Macho-Stadler, et al. (2006) are interested in the outcome of a merger game between identical firms without any antitrust agency present, our focus is on the effect of the agency's presence, and in particular on how that presence spells out when firms are different.

In many analyses of endogenous mergers, it is assumed that only one merger can happen, and so the interest centres on which one; see, e.g., Fridolfsson and Stennek (2005b). The interest in the literature in the study of sequential mergers, where one merger decision is followed by one or more others, starts with Caves (1991). Kamien and Zang (1993) extend their 1990 paper to a situation where a sequence of mergers is allowed. Nilssen and Sørgard (1998) analyze sequential merger decisions made by disjoint sets of firms, while FauliOller (2000) and Neary (2007) relatedly analyze sequential mergers in situations where acquirers and targets belong to disjoint sets. Salvo (2010) extends the Nilssen-Sørgard framework in order to discuss sequential cross-border mergers. Garcia, et al. (2018) set up a model of sequential mergers to discuss whether firms merge in order to facilitate collusion; instead of modeling an antitrust authority explicitly, as we do here, they assume that any merger to monopoly is forbidden. The present study is alone in having the number of mergers carried out determined endogenously.

The need for a forward-looking merger policy in situations with sequential merger decisions is pointed out by Nilssen and Sørgard (1998), observing that the safe-harbor criterion of Farrell and Shapiro (1990) may accept too many mergers when used myopically. Brito (2005) discusses how the endogenousmerger perspective can provide the antitrust authority with a revealed-preference argument for putting an upper limit on a proposed merger's efficiency gains: a proposed merger must be more profitable than those not proposed. Seldeslachts, et al. (2009) study empirically whether merger prohibitions have a deterrence effect on future merger proposals.

Incorporating the antitrust authority's decisions into the analysis of sequential mergers, with each decision by firms to merge followed by a decision by the antitrust authority whether or not to accept, has been done only very recently. In fact, several of the earlier studies explicitly have to restrict firms from merging to monopoly in order to counter-balance the absence of the antitrust authority from their models. Recent work, starting with Lyons (2003), does incorporate the antitrust authority and focuses on how the agency's objective as well as features of the merging process - not least important of which is the fact that merger proposals are picked by firms, not by the authority - affect equilibrium outcomes, themes that also show up in the present work. ${ }^{9}$

\footnotetext{
${ }^{8} \mathrm{~A}$ protocol is a sequence of proposers and, for each proposer, a sequence of respondents. Our protocol is simple: with pairwise mergers, there is, for each proposer, a single respondent.

${ }^{9}$ In addition to Lyons (2003), see, e.g., Armstrong and Vickers (2010), Nocke and Whinston
} 
In this line of research, the analyses closest to ours are by Motta and Vasconcelos (2005), and Nocke and Whinston (2010). Motta and Vasconcelos (2005) model a sequence of two merger decisions, with the antitrust authority being present to approve any merger proposals. ${ }^{10}$ They limit themselves to the case of symmetry, where, at the outset, firms are of equal size; in contrast, it is by introducing asymmetry that we are able to explore both the existence of pill sweetening and the extent of free riding. Their main focus is on the effect of the antitrust authority being myopic. For this purpose, they pay particular attention to cases where, in their model, non-merging firms exit after a merger. In contrast, we only consider cases where, whatever mergers having taken place, all firms are profitable. Moreover, while we also do an analysis of the case of a myopic antitrust authority, in Section 5 below, we keep our sequential merger game while doing so, while Motta and Vasconcelos equate the analysis of a myopic antitrust authority with a static merger game, where only a single merger is on the table. As our analysis shows, myopia has effects on the equilibrium outcome, in particular with respect to the prevalence of the free-riding motive, that such a static approach to myopia does not uncover.

Nocke and Whinston (2010) find conditions under which, in a model of sequential mergers, it is optimal for the antitrust authority to evaluate mergers completely myopically. We depart from them in our theory of mergers: in our analysis, the cost of the merged firm is tied to the sizes of the merging firms, with bigger mergers having lower costs, while there is no such connection in Nocke and Whinston (2010). ${ }^{11}$ Also, Nocke and Whinston (2010) restrict attention to cases where the sequence of mergers involves disjoint sets of firms, while we allow the sets of merging firms to overlap. ${ }^{12}$ Finally, we simplify our analysis by having product-market competition at the end only, while Nocke and Whinston (2010) have it after each stage of merger proposal.

Our focus is on firms' incentives not to carry out a merger in cases where it, seen in isolation, would be profitable. The opposite concern, namely, firms' incentives to merge in cases where the merger, seen in isolation, is unprofitable, has been highlighted by several authors. The first to discuss the preemptive motive for horizontal merger are Nilssen and Sørgard (1998): a group of firms may choose to merge in order to stop another merger from taking place. This preemptive motive to merge also shows up in the work of Horn and Persson (2001a), Brito (2003), Fridolfsson and Stennek (2005b), Pesendorfer (2005), and Macho-Stadler, et al. (2006). None of these models incorporates an antitrust

(2013), and Burguet and Caminal (2015).

${ }^{10}$ Related to the work of Motta and Vasconcelos (2005) is that of Fumagalli and Vasconcelos (2009), who discuss a model of sequential mergers with multiple antitrust authorities, two national ones and one supranational, and the effect of varying the antitrust authorities' objectives.

${ }^{11}$ But see Mermelstein, et al. (2018), who allow for efficiency gains from mergers and also allow for firms to grow organically, i.e., through investments, in addition to through mergers.

${ }^{12}$ But see Jeziorski (2015), who, in his study of the US radio broadcasting industry, extends the analysis of Nocke and Whinston (2010) to allow for overlapping mergers. Also Nocke and Whinston (2013) allow overlapping sets of (potentially) merging firms, but they do not discuss dynamics. 
authority into the analysis, though.

The paper is organized as follows. In the next section, we present the model as well as the social optimum. In Section 3, we present the equilibrium outcome and the pill-sweetening motive not to merge early, as well as the other two motives discussed above. In Section 4, we take issue with the model of Section 3 being too focused on firms' interest in merging to monopoly and discuss an extension to the case of four firms, in which more of the interest centres on firms' incentives to merge to duopoly. In Section 5 , we discuss how our results hinge on some crucial assumptions made, and we also discuss some possible alterations of our model. Section 6 concludes. The Appendix contains the formal analysis.

\section{The model}

We model a game consisting of two parts. The first part is a merger game, a sequence of pairwise mergers starting from a status-quo situation of an industry with three independent firms. ${ }^{13}$ The second part is a product-market competition game among the entities that are present after the merger game. We are looking for the subgame-perfect equilibrium of the whole game.

The benefit of focusing on a three-firm industry is that the analysis is transparent with so few firms. As discussed in the Introduction, though, some aspects of the pill-sweetening motive for not merging are best spelled out in an analysis of an industry with more firms than that. We therefore present an analysis of the four-firm case in Section 4 below. In particular, with four firms, there may be incentives for pill sweetening in order to obtain a duopoly, while in the present case of three firms, a sequence of two mergers inevitably leads to complete monopoly.

Following any merger proposal is a decision by the antitrust authority (henceforth, AA) whether to approve the proposed merger or not. The merger game stops when there are no more mergers to form, either because they are not profitable, because they would not be approved, or because the industry has reached complete monopoly.

At the outset, i.e., before any mergers, the supply side consists of three firms, belonging to the set $S:=\{1,2,3\}$ of firms.

The product market has an inverse demand given by

$$
p(X)=a-X,
$$

where $a$ is a parameter describing the size of the market, ${ }^{14}$ and $X$ is total supply from the firms in the industry. Firms compete by setting quantities, i.e., by playing a Cournot game.

\footnotetext{
${ }^{13}$ When we, in our analysis, disregard the possibility of a threewise merger straight to monopoly, we do it without loss of generality. Clearly, such a merger would only be allowed, and therefore only happen, when it would be socially optimum, and so allowing it would not affect the prevalence of pill sweetening.

${ }^{14}$ The market demand can, in other words, be written: $D(p)=a-p$. It is, of course, only because $D^{\prime}(p)=-1$ - and, correspondingly, $p^{\prime}(X)=-1$ - that we this simply can interpret $a$ as a demand shifter and thus as a measure of market size.
} 
In order to allow for efficiency effects from mergers, we assume that each firm at the outset has a cost function given by

$$
C_{i}\left(x_{i}\right)=\frac{x_{i}}{k_{i}}, i \in S,
$$

where $x_{i}$ is the production quantity of firm $i, \sum_{i \in S} k_{i}=1$, and $k_{i}>0, \forall i$. One can think of $k_{i}$ as the amount available to firm $i$ of a production factor whose total supply in the industry is given. For a given distribution of this factor among the firms, the formulation in (1) entails constant returns to scale. The more a firm has available of this factor, however, the lower are the costs of production. ${ }^{15}$

We focus on a special case of asymmetrically sized firms where one firm, firm 1 , is of a different size than the other two firms, which both are of the same size. In particular, we make the assumption that

$$
k_{1}=k \in(0,1), \text { and } k_{2}=k_{3}=\frac{1-k}{2} .
$$

A merger creates a new unit that has lower costs than the merging firms. In particular, if a set $M \subseteq S$ of firms merge, then the merged entity has a cost function

$$
C_{M}\left(x_{M}\right)=\frac{x_{M}}{k_{M}},
$$

where $x_{M}$ is the production quantity of the merged entity, and $k_{M}=\sum_{i \in M} k_{i}$.

The outcome of the merger game is a market configuration, or a partition of $S$. There are four principally different such configurations: $S Q$ - Status Quo, with no merger and the configuration $\Theta^{S Q}:=\{1,2,3\} ; P O$ - Partial Out, with a merger between the two firms other than firm 1 and the configuration $\Theta^{P O}:=$ $\{1,23\} ;{ }^{16} P I-$ Partial In, with a merger between firm 1 and one other firm and a configuration such as $\Theta^{P I}:=\{12,3\} ;{ }^{17}$ and $C M$ - Complete Monopoly, with a merger between all three firms and the configuration $\Theta^{C M}:=\{123\}$. Let $\Xi$ denote the set of possible outcomes of the merger game, and let $\Theta$ denote the corresponding set of market configurations; i.e., $\Xi:=\{S Q, P O, P I, C M\}$, and $\Theta:=\left\{\Theta^{\xi}\right\}_{\xi \in \Xi} \cdot$

\footnotetext{
${ }^{15}$ To be exact, the function in (1) should be viewed as a short-run cost function where one production factor, $k_{i}$, is fixed. This formulation is similar to other cost functions used in the merger literature; see, e.g., Horn and Persson (2001b), Motta and Vasconcelos (2005), Vasconcelos (2005), Fumagalli and Vasconcelos (2009), and Cunha and Vasconcelos (2018). The introduction of efficiency effects from mergers in this manner originates with Perry and Porter (1985). Their focus is on cases where the long-run cost function $C\left(x_{i}, k_{i}\right)$ is homogeneous of degree one, which implies that the short-run one features decreasing returns to scale. In Section 5, we discuss equilibrium outcomes of our model when the short-run cost function exhibits non-constant returns to scale.

${ }^{16}$ By the convention we adopt here, $\{1,23\}$ denotes a two-firm industry consisting of firm 1 and the entity stemming from the merger between firms 2 and 3 . With this notation, the set of non-empty subsets of $S$ is $\{1,2,3,12,13,23,123\}$.

${ }^{17}$ Since firms 2 and 3 are identical, letting $\Theta^{P I}=\{13,2\}$ would be the same.
} 
A firm's profit is given by

$$
\pi_{i}=p(X) x_{i}-C_{i}\left(x_{i}\right)=\left(a-X-\frac{1}{k_{i}}\right) x_{i}, i \in \Theta^{\xi}, \xi \in \Xi .
$$

Because of linearity in demand, consumer surplus in outcome $\xi$ is simply

$$
C S^{\xi}=\frac{1}{2}\left(\sum_{i \in \Theta^{\xi}} x_{i}\right)^{2}, \xi \in \Xi .
$$

Moreover, as long as all firms' production quantities are positive, which is assumed in the following, the equilibrium profit of firm $i$ in outcome $\xi$ equals $^{18}$

$$
\pi_{i}^{\xi}=x_{i}^{2}, i \in \Theta^{\xi}, \xi \in \Xi
$$

and total profit in the industry in outcome $\xi$ equals

$$
\Pi^{\xi}=\sum_{i \in \Theta^{\xi}} \pi_{i}^{\xi}=\sum_{i \in \Theta^{\xi}} x_{i}^{2}, \xi \in \Xi .
$$

Both the AA and the firms are forward-looking. This means that, when making a decision, each player compares the eventual outcomes that follow each choice. $^{19}$

The AA applies the total-welfare standard when assessing merger proposals, i.e., it seeks the highest $T W$, where, in outcome $\xi$,

$$
T W^{\xi}:=C S^{\xi}+\Pi^{\xi}=\frac{1}{2}\left(\sum_{i \in \Theta^{\xi}} x_{i}\right)^{2}+\left(\sum_{i \in \Theta^{\xi}} x_{i}^{2}\right)=X^{2}\left(\frac{1}{2}+H\right),
$$

where $H:=\sum_{i \in \Theta \xi} s_{i}^{2}$ is the Herfindahl index measuring market concentration, with $s_{i}:=\frac{x_{i}}{X}$ being the market share of firm $i \in \Theta^{\xi}, \xi \in \Xi$. In other words, by the total-welfare standard, there are two effects of a merger: it increases concentration and efficiency, and therefore firms' profits, which is good, and it changes total output, which is good when the change is positive, but very often is bad because the merger entails a lower total output. The AA approves a merger when the former effect outweighs the latter. In Section 5 below, we discuss how equilibrium outcomes are affected by variations in the relative weights put by the AA on consumer surplus and total profit, i.e., by the AA getting closer to the consumer welfare standard.

The model has two exogenous parameters: $a$, which measures the market size; and $k$, which measures firm asymmetry. We restrict interest to those

\footnotetext{
${ }^{18}$ See for example Motta (2004, sec. 8.4.1.2); conditions ensuring positive quantities are discussed in the Appendix. Note that we this way disregard cases where a merger entails exit by the non-merging firm (or firms, in the four-firm analysis of Section 4), an aspect of our analysis that contrasts it to that of Motta and Vasconcelos (2005).

${ }^{19}$ In Section 5 below, we discuss an alternative assumption, letting firms be forward-looking while the AA is myopic.
} 
combinations $(k, a)$ for which all firms present produce positive quantities in all the four outcomes outlined above. We denote by $Z$ the set of all such parameter combinations, and this set is also depicted in the Figures we present below.

We assume that a merger is not proposed if it subsequently will be turned down by the AA. In assessing whether a merger is profitable, a firm compares the profit it gains from this merger with the alternative, which is not to merge. Since firms are far-sighted, they compare profits obtained from the outcomes that eventually prevail after the various alternatives. We assume that the two firms involved in a merger engage in Nash bargaining, splitting evenly the extra profit gained from merging. For example, when firm 1 merges with firm 2 and we move from $S Q$ to $P I$, firm 1's share of the merged entity's profit is:

$$
\frac{1}{2}\left(\pi_{12}^{P I}-\pi_{1}^{S Q}-\pi_{2}^{S Q}\right)+\pi_{1}^{S Q}=\frac{1}{2}\left(\pi_{12}^{P I}+\pi_{1}^{S Q}-\pi_{2}^{S Q}\right) .
$$

In other words, firm 1 gets its stand-alone profit that it would get by not merging, $\pi_{1}^{S Q}$, plus half of the extra profit that is gained from the merger, which is the profit of the merged entity minus the two stand-alone profits: $\pi_{12}^{P I}-\pi_{1}^{S Q}-\pi_{2}^{S Q}$. As we see, the two events "firm 1 merging with firm 2" and "firm 2 merging with firm 1" have the same outcome, also in terms of profits, so that we can use the two terms interchangeably. ${ }^{20}$

The merger game - details of which are provided in Figure 1 - consists of eight decision nodes. ${ }^{21}$ Four of these nodes are called merger nodes, numbered 1 through 4 in Figure 1: at each merger node, if that node is reached, a decision whether to propose a merger is made. After a decision to merge follows an $A A$ node, where the AA decides whether to accept the proposed merger; AA nodes are numbered $1 A$ through $4 A$ in Figure 1.

The game starts out with firm 1 and one of the other two firms deciding whether or not to merge; this is node 1 in Figure $1 .{ }^{22}$ Since the other two firms are of equal size, we randomly assign firm 2 the role of firm 1's merging mate. A merger is profitable if the joint profit of the merging firms is higher following a merger proposal than following a decision not to merge. Note that the crucial issue is not simply whether the profit of the merged firm 12 in situation $P I$ is higher than the sum of their profits in situation $S Q$. Rather, the firms at node 1 take into consideration the actions along the equilibrium path following each of their alternatives.

Note that the figures depicting the merger game single out one firm at each node as taking the decision whether or not to merge. This serves merely to

\footnotetext{
${ }^{20}$ But see Sec 5 for a brief discussion of the effects of having other ways of splitting the gains from merger than equally.

${ }^{21}$ In a game-theoretic sense, the number of decision nodes is greater than 8 . As will become clear in the text, some of our 8 nodes can be reached by different routes through the graph in Figure 1.

${ }^{22}$ Having the differently-sized firm 1 move first is the only interesting case. In Section 5 below, we discuss why having one of the other firms move first is of less interest. Giving firm 1 the decision power on merging but not the full bargaining power in the negotiations with the merging partner is of little significance for our results, as we discuss in Section 5.
} 
simplify the exposition and has, as already discussed, no significance, since extra profits gained from merging are split equally.

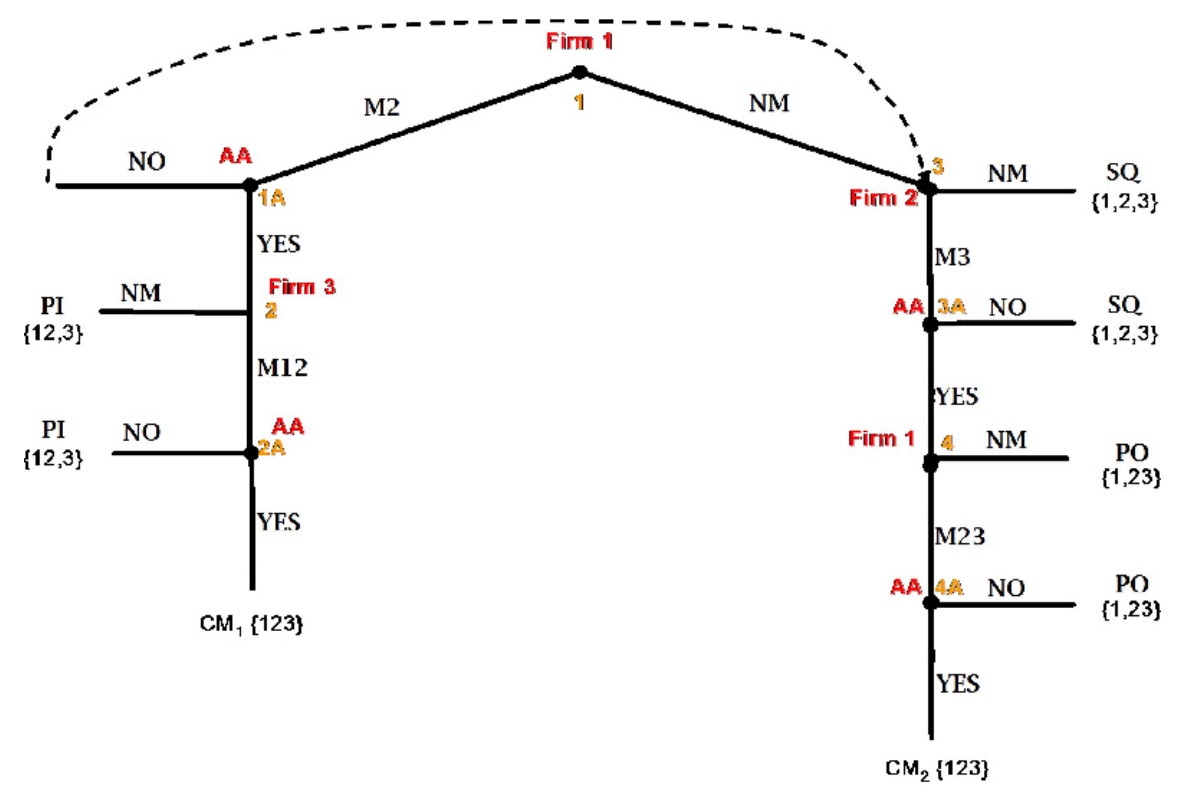

Figure 1. The merger game.

If firm 1 and 2 propose a merger, then the AA next makes a decision whether to approve the merger or not; this is node $1 A$ in Figure 1 . If AA says No, then we are at node 3 , in the same situation as if firm 1 and 2 had decided not to merge; see below. If AA says Yes, then the remaining firms 12 and 3 are given the choice to propose a merger; this is node 2 in Figure 1. If these firms decide not to merge, then the process stops, and we end in a $P I$ situation, with the firms in $\{12,3\}$ playing a Cournot game. If firms 12 and 3 decide to merge, then AA makes a decision whether to approve or not; this is node $2 A$ in Figure 1 . If AA says No, then the merger game again ends in a $P I$ situation. If AA says Yes, then we arrive at $C M$, with 123 a monopolist in the industry.

If, at node 1 , firms 1 and 2 decide not to merge (or if, at node $1 A$, AA says No), then the two equal-sized firms 2 and 3 decide whether or not to merge; this is node 3 in Figure 1. If firms 2 and 3 decide not to merge, then both alternatives of pairwise mergers have been tried - firm 1 with one other firm, and the two other firms together - with negative responses, so that the merger game ends with the $S Q$ outcome.

If firms 2 and 3 propose a merger, however, we move on to AA deciding whether or not to approve it; this is node $3 A$ in Figure 1 . If the AA does not approve, then again the merger game ends with $S Q$. If AA approves, on the other hand, then a new situation has arisen with firms 1 and 23 in place. Next, therefore, these two firms choose whether or not to merge; this is node 4 in Figure 1. If no merger is proposed, then the merger game ends in the $P O$ 
outcome, with the firms in $\{1,23\}$ playing a Cournot game. If firms 1 and 23 propose to merge, however, then AA has to approve the merger or not; this is the final decision node $4 A$ in Figure 1. If AA says No to the merger, then the merger game ends in $P O$, while if it says Yes, then we end in $C M$.

A merger is proposed in this game only if it will be accepted by the AA. We can thus simplify the exposition by subsuming the AA nodes that lie beneath the merger nodes. The simple picture of the merger game is the one given in Figure 2.

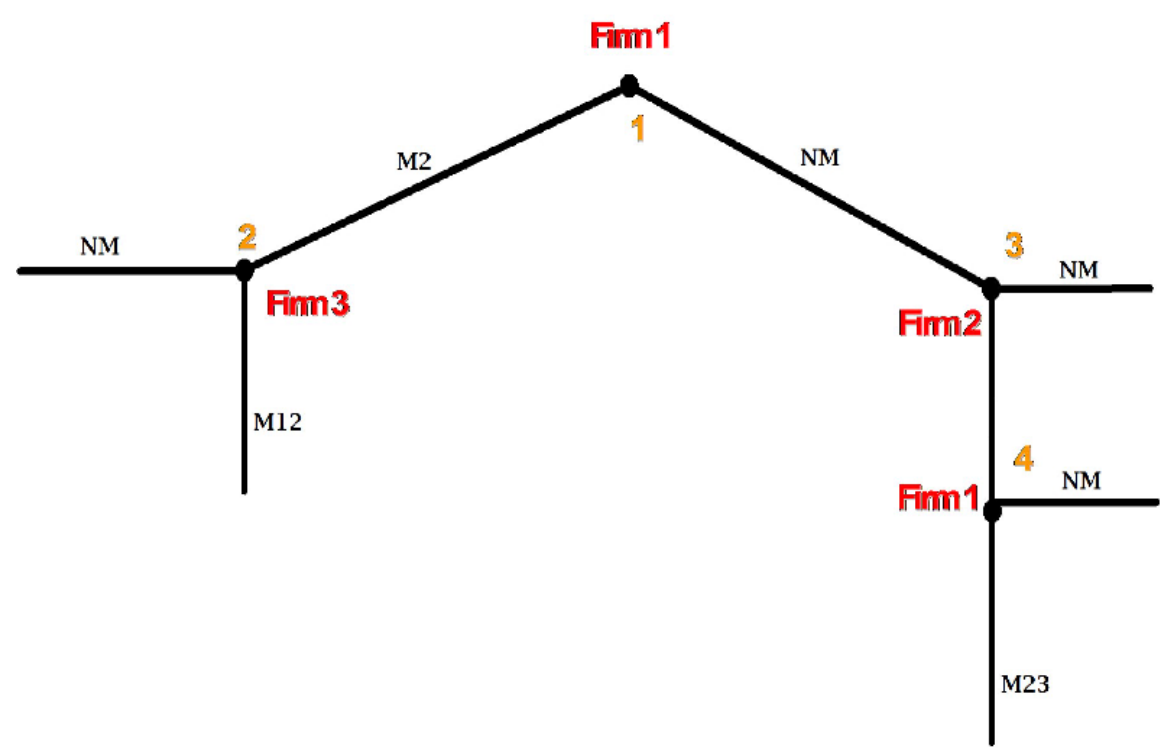

Figure 2. The simplified merger game.

As can be seen from Figures 1 and 2, there are two different ways to arrive at $C M$, and we want to keep the two apart in the continuation. Therefore, we denote by $C M_{1}$ complete monopoly following from firms 1 and 2 then firms 12 and 3 merging (nodes 1-2 in Figure 2), while we denote by $C M_{2}$ complete monopoly following from firm 1 first not taking part in a merger, then firms 2 and 3 merging and finally firms 1 and 23 merging (nodes 1-3-4 in Figure 2). This completes the description of the merger game.

As noted, our focus is on the set $Z$ of combinations $(k, a)$ of firm asymmetry and market size for which equilibrium quantities are positive in the productmarket stage, irrespective of the outcome of the merger game. Our aim is, for each combination $(k, a) \in Z$, to find the equilibrium outcome of the game. We do this through backward induction by first solving the product-market game in each of the merger-game outcomes. Thereafter, we proceed by looking at each node $n \in N$ to determine, for each $(k, a) \in Z$, what the eventual outcome of the merger game is. The details of the formal analysis are in the Appendix.

We represent the results of our analysis by way of figures depicting the parameter space, i.e., the set $Z$ of combinations of the two key parameters 
$k$ and $a$ that are of interest here. Below, starting with Figure 3, we present several such figures of the space $Z$. In these figures, the market size is measured vertically by the parameter $a$ : the higher is $a$, the higher is the demand in the market, and thus the larger is the scope for more firms present in the market. The asymmetry of firms is measured horizontally by the parameter $k$. At $k=\frac{1}{3}$, firms are identical. As $k$ falls from $\frac{1}{3}$, firm 1, the differently sized firm, becomes smaller and smaller and has higher and higher costs, while the opposite is the case with the other two firms. On the other hand, as $k$ increases from $\frac{1}{3}$, it is firm 1 that becomes the big firm and has lower and lower costs as $k$ increases, while the opposite is true for the other two firms, which now are smaller than firm 1. For a given market size $a$, the area within the space $Z$ are values of $k$ for which the difference between the firms is not so big that the small firm(s) will exit. As $a$ increases, a wider range of firm asymmetries is viable. ${ }^{23}$

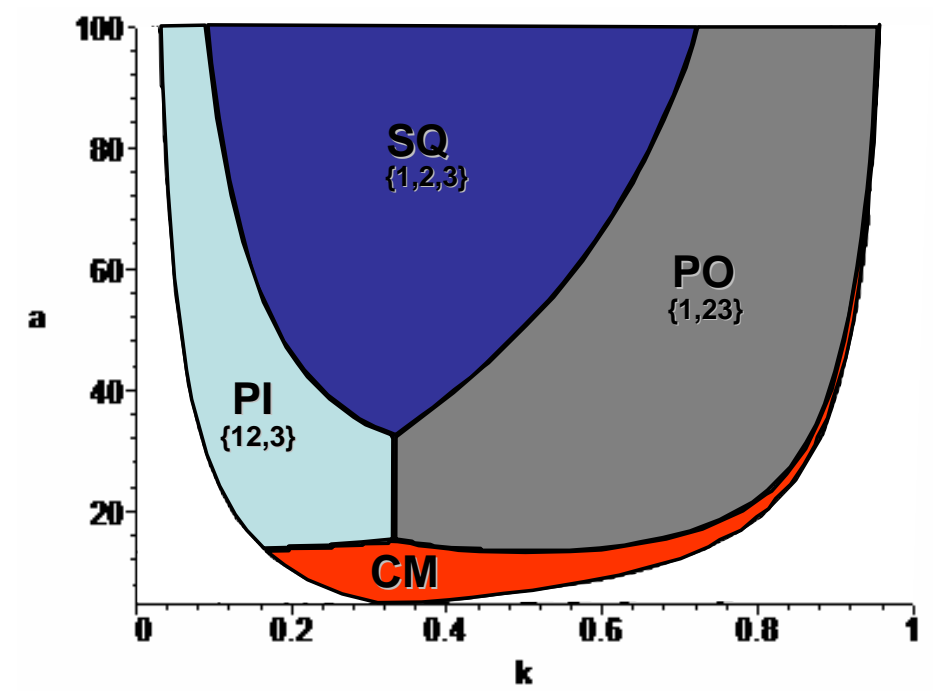

Figure 3. Socially optimum market structures.

Before discussing, in the next Section, the equilibrium outcome of our game, we take a look at the socially optimum market structure, i.e., what a social planner would implement if he could decide the market structure without playing the merger game. ${ }^{24}$ The social planner's choice is presented in Figure 3 where, for each $(k, a) \in Z$, the socially optimal outcome is given. We see that all four possible market structures are represented. When the market is large (high $a)$ and the firms are symmetric enough (intermediate values of $k$ ), the social planner prefers the status quo $(S Q)$. When firm 1 is relatively small, the social planner prefers the Partial In $(P I)$ outcome, with firm 1 merging with one of

\footnotetext{
${ }^{23}$ In these figures, the vertical axis is truncated at 4.5 for convenience. The reason is that, for $a<4.5$, not even monopoly is profitable, whatever $k$ is.

${ }^{24}$ The procedure to determine the socially optimum market structure is: for each $(k, a) \in Z$, identify the market structure that maximizes $T W$, i.e., that picks the $\xi \in \Xi$ with the highest $T W^{\xi}$, given in $(2)$.
} 
the other firms. When, on the other hand, firm 1 is relatively big, the social planner prefers the Partial Out $(P O)$ outcome, with firm 1 sitting on the outside while the other two firms merge. In both instances, the social planner sees the benefit of small firms merging in order to save on costs and create balance in the market. Finally, when the market size $a$ is very small, the social planner prefers Complete Monopoly $(C M)$.

The picture in Figure 3 coincides exactly with the equilibrium outcomes of the game starting at node $1 A$, where the AA decides whether to accept a merger proposal from firm 1. This equilibrium outcome is depicted in Figure A3 in the Appendix. This means that the equilibrium outcomes, presented below, deviate from social optimum solely because firms have the option not to merge at node 1, i.e., to move the merger game to node 3 in Figure 1 rather than to node $1 \mathrm{~A}$.

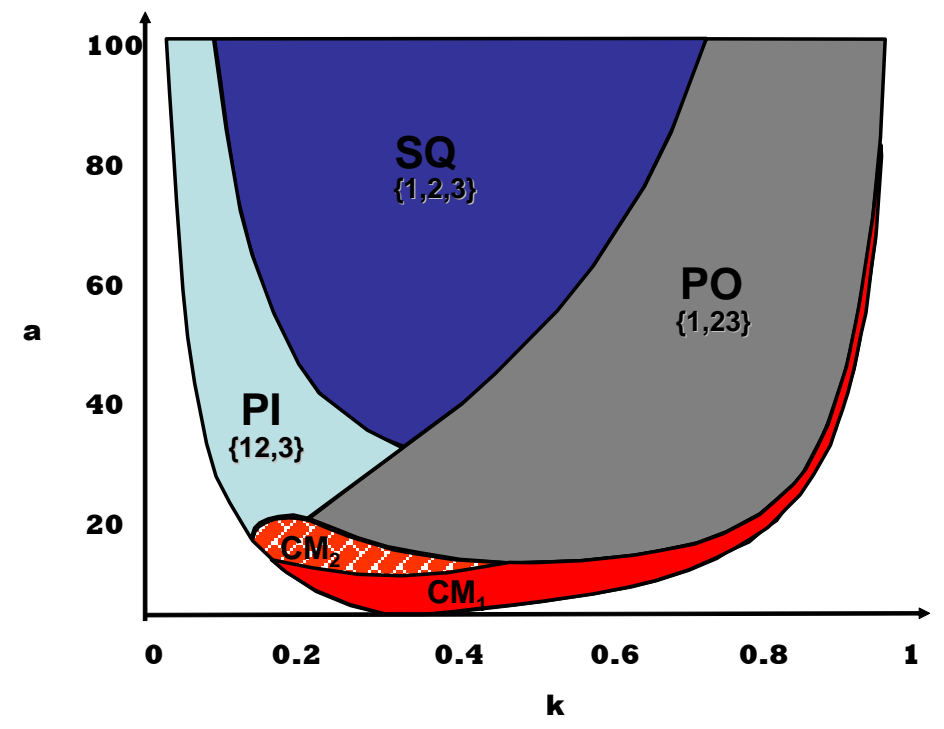

Figure 4. Equilibrium outcomes.

\section{$3 \quad$ Equilibrium outcome}

From the equilibrium analysis in the Appendix, the picture in Figure 4 emanates. When comparing this Figure with Figure 3 above, we see that prevalence of two mergers, so that the market ends up in complete monopoly, is higher in equilibrium than in social optimum. We see that also the $P O$ outcome, where there is a single merger between the two equal-sized firms 2 and 3, is more prevalent in equilibrium than what social optimum prescribes. Note, in Figure 4, how we have split the $C M$ area in two, $C M_{1}$ and $C M_{2}$, corresponding to complete monopoly being reached by firms 1 and 2 at node 1 choosing to merge or not, respectively. The outcomes $S Q, P O$, and $C M_{2}$ are reached by these 
firms not merging at the start of the game, while the outcomes $P I$ and $C M_{1}$ are reached by these firms starting with proposing a merger.

In most cases where firms 1 and 2 choose not to merge, it would not make a difference whether they did or not, since a merger proposal would have been rejected by the $\mathrm{AA}$ at node $1 A$ anyway. The interest centres, therefore, on those cases where these firms' profits are strictly better from not merging than from merging at node 1. Accordingly, in Figure 5, we have drawn the solution again, highlighting the areas in which firms 1 and 2 choose not to merge for such strategic reasons.

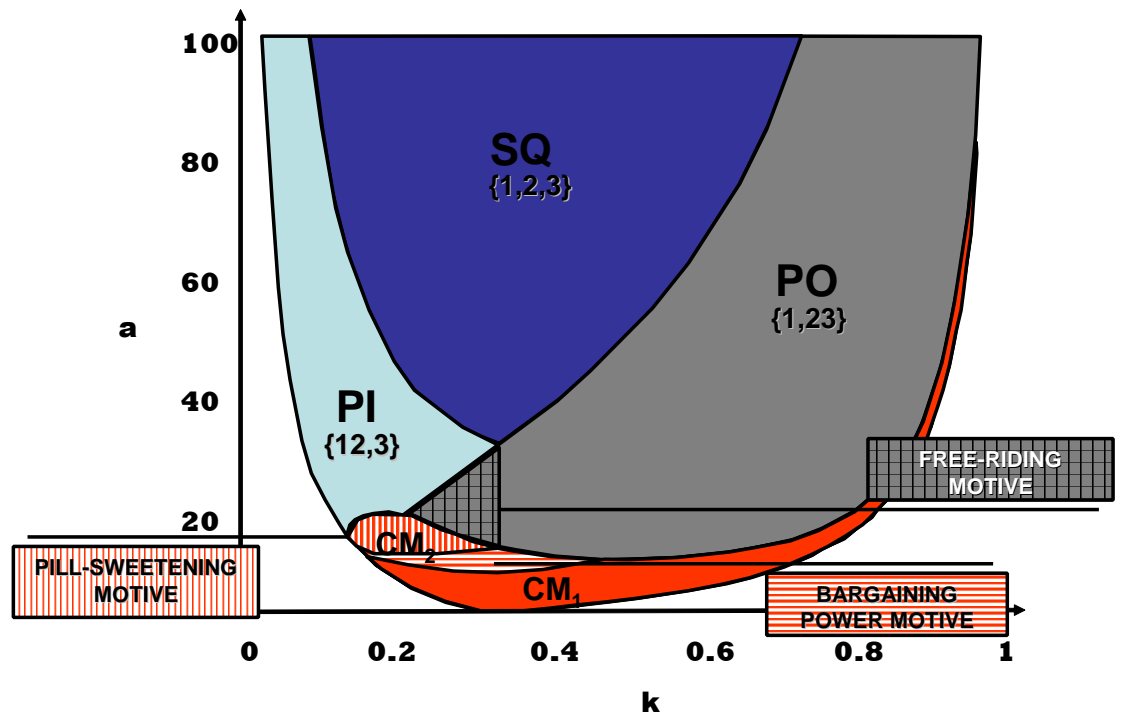

Figure 5. Three motives for not merging.

Figure 5 highlights the pill-sweetening motive for not merging at the first opportunity: firms 1 and 2 choose not to merge at node 1 in order to get the AA to accept an additional merger, in situations where such an additional merger would not be allowed in case of an immediate merger between these firms. Such cases occur when firm 1 is smaller than the other two firms (i.e., where $k<\frac{1}{3}$ ): while the AA would not allow firm 3, a big firm, to join firm 12, it accepts firm 1, a small firm, joining the big firm 23; see the vertically hatched area in Figure $5{ }^{25}$ The equilibrium path leading to pill sweetening is depicted in panel (a) of Figure 6. In that Figure, a thick line emanating from a merger node indicates which decision is taken at that node. Thus, at node 1 , firms 1 and 2 choose not

\footnotetext{
${ }^{25}$ The only way the pill-sweetening motive can occur in our model is by firm 1 in the future joining a unit that has merged in the meantime, i.e., the merged entity 23 . With more firms in the industry at the outset, there is a scope for the pill-sweetening motive to occur also through firm 1 in the future merging with another firm than the unit that has merged in the meantime, in order to restore some of the imbalance in the industry created by the first merger; see our discussion in Section 4.
} 
to merge. At node 2, firms 12 and 3, if called upon to play, would choose not to merge, since such a merger would be blocked by the AA. At nodes 3 and 4, on the other hand, mergers are proposed and subsequently approved.

In order to complete the picture, Figure 5 also points out occurrences of the other two motives for not merging that we discussed in the Introduction. The bargaining-power motive occurs in cases where the outcome would be complete monopoly whatever the choice of firms 1 and 2 at node 1 is, even in the presence of an antitrust authority; see the horizontally hatched area in Figure 5. This happens for market sizes slightly less than for pill sweetening. The corresponding equilibrium play is depicted in panel (b) of Figure 6. Compared to pill sweetening, we see that market size is now so small that a merger proposal by firms 12 and 3 at node 2 would have been accepted by the AA at node $2 A$. This means that firm 1 can obtain complete monopoly whichever its choice at node 1 , but it prefers waiting and joining the merged unit only at node 4 . The option to wait is convenient in case firm 1 is relatively small ( $k$ low) and the market is relatively big ( $a$ large, conditioned on the AA allowing complete monopoly): When firm 1 is small, it has limited bargaining power when it stands alone and would get a low share of the equilibrium (monopoly) profit if it joins a merger immediately. By letting the other two firms merge first, firm 1 acquires a stronger bargaining position as it obtains an inside option of free-riding on the others' merger since that merger leads to higher profit also for the non-merging firm 1 . That is why, by letting the other two firms merge first, firm 1 can achieve a higher share of the monopoly profit.
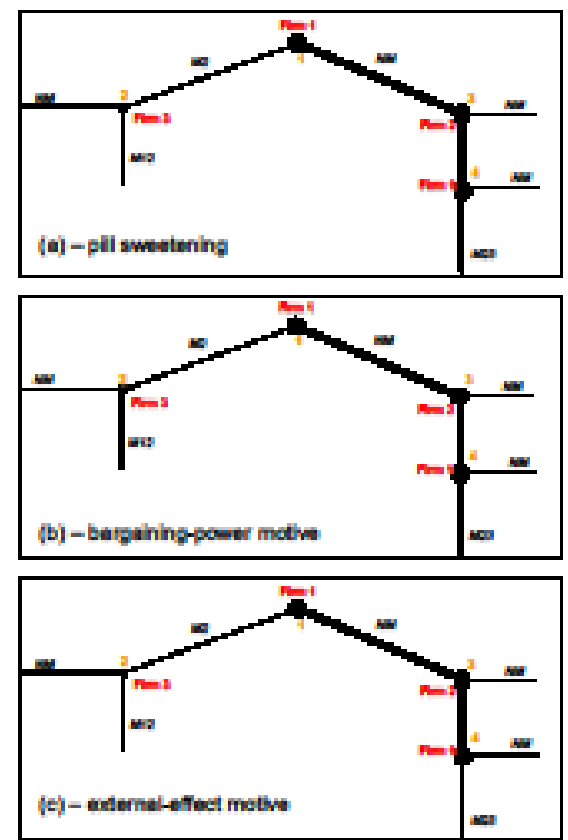

Figure 6. Equilibrium paths for the different waiting motives. 
Finally, we also have instances of the free-riding motive in Figure 5. There are cases, with a market of medium size, where complete monopoly is not allowed, but where the AA prefers one merger taking place to none and firm 1 prefers being outside that single merger. The equilibrium play is depicted in panel (c) of Figure 6. If, starting out in a situation with pill sweetening in Figure 5, the market size is increased, then the AA would no longer be interested in complete monopoly. Thus, firm 1 compares the profitability of the two singlemerger outcomes $P O$ and $P I$. Free riding occurs when it is better for firm 1 to be the outsider to a merger in the $P O$ outcome than being on the inside of a merger in the $P I$ outcome. As shown by the cross-hatched area in Figure 5, this happens when firm 1 is slightly smaller than the others: it is more profitable for it to let the other two firms merge, enjoying the free ride, than merging with one of them and suffering from the contraction in output that follows. In fact, firm 1, being smaller, obtains more concentration in the industry by not taking part in a merger itself and instead letting the other firms have the one merger that the AA is going to allow.

\section{A richer model: four firms}

In the three-firm model of Section 2, a sequence of two mergers is bound to lead to complete monopoly. So while the analysis is more transparent with only three firms involved, the scope for pill sweetening to be a motivation for not merging early is limited by this: while the AA may be interested in more than one mergers, complete monopoly may be a bit too much for it. To see how the scope for pill sweetening is increased when there are more than three firms, we present in this Section an analysis of a case with four firms. We will be able to see how pill sweetening now shows up as an effort by the first-moving firm not so much to get complete monopolization of the market but rather to obtain merger to duopoly: while an immediate merger by firm 1 may imply only a single merger going through the antitrust authority, passing up on that merger opportunity and instead merging later, to counter another merger that has been carried through in the meantime, opens up for the antitrust authority to accept a second merger if it helps mitigating any imbalance in the industry created by that other merger. As we will see below, with four firms, that second merger is often between those two firms that did not already take part in a merger so far. This four-firm analysis also strengthens the empirical prediction from our model, that big mergers happen before small ones.

The set of firms at the outset is now $S:=\{1,2,3,4\}$. Firm 1 is of a different size then the other three, who are identical. Thus, $k_{1}=k \in(0,1)$, while $k_{2}=k_{3}=k_{4}=\frac{1-k}{3}$. The symmetric case is at $k=\frac{1}{4}$. We stick to considering pairwise mergers only.

The merger game in the four-firm case is depicted in Figure 7 and consists of 10 merger nodes. This Figure parallels that of Figure 2 in that it only shows nodes where merger decisions are made and subsumes the AA's decision nodes, where decisions are made whether to accept proposed mergers. The full picture 
is shown in the Appendix.

In the four-firm case, there are seven principally different outcomes of the merger game: $S Q$-Status Quo, with no merger and the configuration $\{1,2,3,4\}$; $P O$ - Partial Out merger, with a merger between two equal firms and a configuration such as $\{1,23,4\} ; P I$ - Partial In merger, with a merger between firm 1 and one other firm and a configuration such as $\{12,3,4\} ; F O$ - Full Out merger, with a merger between all three equal firms and the configuration $\{1,234\} ; F I$ - Full In merger, with a merger between firm 1 and two of the other firms and a configuration such as $\{123,4\} ; A D$ - Asymmetric Duopoly, with two pairwise mergers, one involving firm 1 , and a configuration such as $\{12,34\}$; and $C M-$ Complete Monopoly, with a merger between all four firms and the configuration $\{1234\}$. The new outcomes are $F O, F I$, and $A D$, all three featuring a sequence of two mergers, which now is one merger short of complete monopoly.

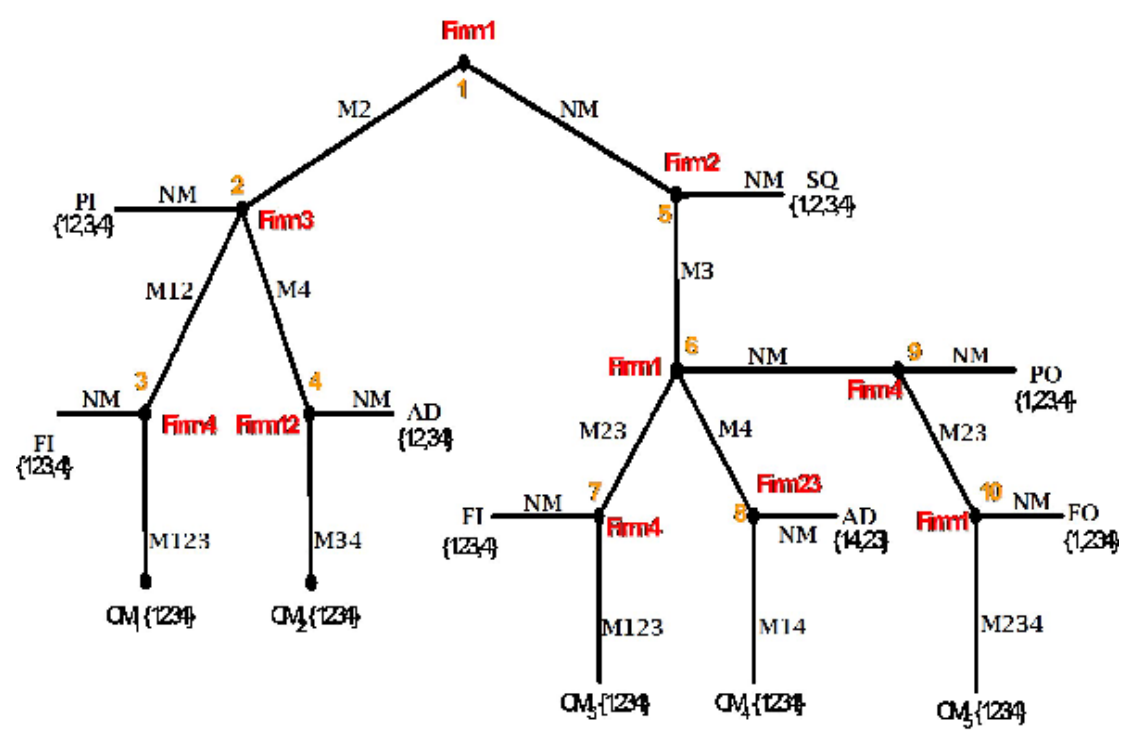

Figure 7. The four-firm merger game.

We now have five different paths to arrive at the Complete Monopoly outcome; they are marked $C M_{1}$ through $C M_{5}$ in the Figure. As it turns out, though, only $C M_{2}$ and $C M_{5}$ occur in equilibrium. Firm 1 has a total of three chances to take part in an merger (nodes 1, 6, and 10 in Figure 7), compared to two chances in the analysis above: it may want to join a merger after two of the others have merged (node 6); and if not, we need to check whether it wants to take part in a merger after all three other firms have merged (node 10). The equilibrium outcome is depicted in Figure 8. ${ }^{26}$

The Figure shows that there is a great variety in possible outcomes, although the $F I$ outcome does not occur in equilibrium for any combination $(k, a)$. It

\footnotetext{
${ }^{26}$ For a complete description and a detailed analysis of the four-firm merger game, see our online appendix.
} 
also shows that firms' decisions to merge again are heavily influenced by what will get through at the AA. When $k$ is large, so that the industry at the outset consists of the big firm 1 and three small ones, firm 1 realizes that its best shot is sitting outside the merger process and letting the small firms merge, either all three $(F O)$ or at least two of them $(P O)$.

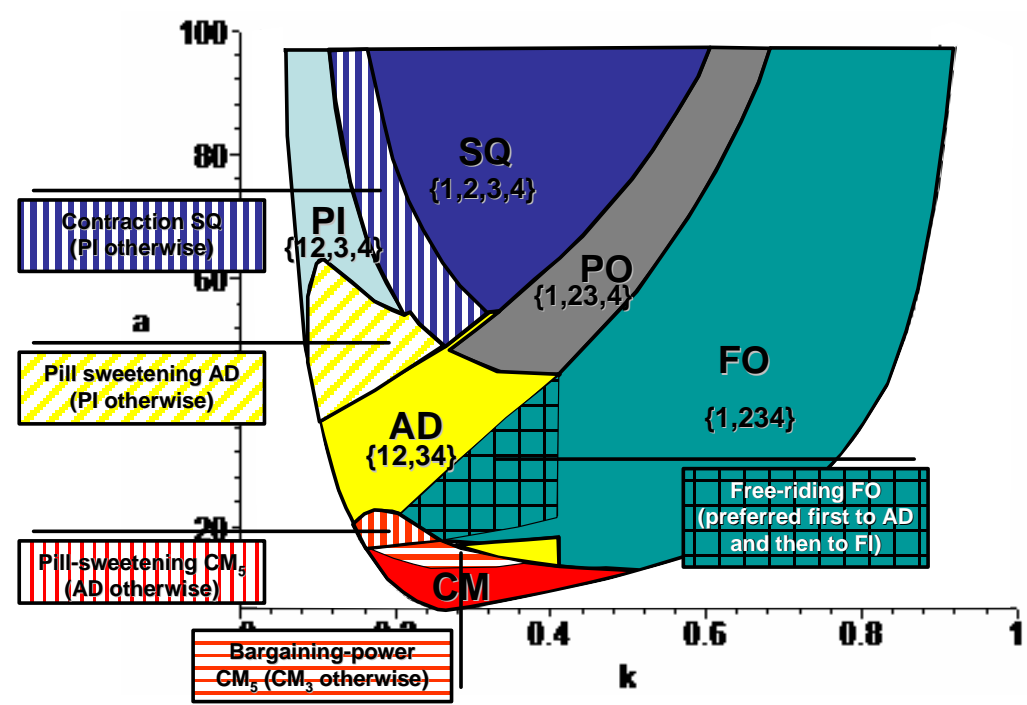

Figure 8. Equilibrium outcome with four firms.

When $k$ is small, so that the industry consists of the small firm 1 and three large ones, there is a potential for at least one of the large firms to get involved in a merger. If $a$ is not very large, then it is actually possible for all the large firms to get involved in merger, as in the $A D$ outcome, with two of the large firms merging with each other and the third one merging with the small firm 1. When $a$ is very small, there is not room for more than one firm in the industry, also by the AA's standard, and so we end up with $C M$. In the opposite end, when $a$ is very large, there is no scope for a merger from the AA's point of view, and $S Q$, the situation we start out with, is also the final outcome.

In Figure 8, we also highlight the combinations $(k, a)$ for which the firm has a strategic motive for not merging at once. Note, in particular, the "Pill sweetening $A D$ " region of the Figure; the equilibrium play leading to this outcome is depicted in Figure 9. In order to obtain a sequence of two mergers, thus turning the industry into an asymmetric duopoly $(A D)$, firm 1 abstains from taking part in a merger at the outset, thereby avoiding the single-merger $P I$ outcome that would follow from an immediate merger, since the AA would decline any merger proposed at node 2 , and instead going for a merger at the next opportunity by joining forces with the other remaining outside firm at node 6 in Figure 9. Firm 1 gets, in other words, an extra merger through the AA by itself abstaining from merger in the first instance. This happens, as Figure 8 indicates, when firm 1 is smaller than the other firms and the market is of medium size. 
Note that pill sweetening also shows up in a manner parallel to the earlier analysis: In order to obtain complete monopoly, firm 1 chooses to pass up on an opportunity to merge, not only once but twice; this is the "Pill sweetening $C M_{5}$ " region of Figure $8{ }^{27}$

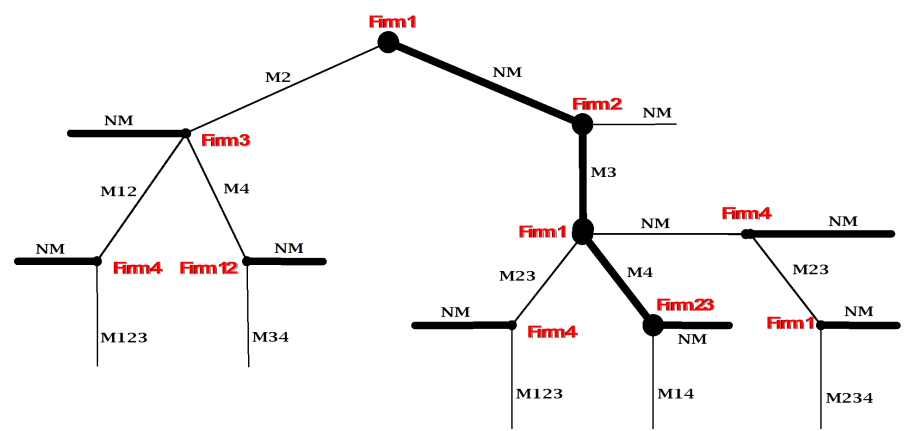

Figure 9. The equilibrium path leading to the "pill-sweeting AD" equilibrium.

All in all, it seems safe to conclude, if only by visual inspections of Figures 5 and 8 , that the prevalence of a firm passing up on opportunities to merge in order to sweeten the pill for the antitrust authorities is only increasing as the number of firms in the industry increases.

\section{Discussion}

This Section contains a discussion of our results. First, in items (i) through (v) below, we take up the five features of our model, already discussed in the Introduction, that are crucial in producing our results. These are: the presence of efficiency gains; asymmetry among firms; the presence of an AA; scale economies; and a sufficient alignment of interest among firms and the AA. Thereafter, in item (vi) below, we discuss the consequences for our analysis of putting restrictions on the AA's ability to being forward-looking when making its decisions. Finally, in items (vii) through (ix) below, we discuss briefly some alternative modelling assumptions having to do with the sequence of moves, the modelling of asymmetry, and the bargaining power among merging firms.

(i) Efficiency gains from merger. The presence of efficiency gains is instrumental in creating an interest on the part of the AA in having mergers to take

\footnotetext{
${ }^{27}$ The bargaining-power and free-riding motives show up in Figure 8 in much the same way as we saw in the analysis of the three-firm case. In addition, we observe a new motive for not merging that did not occur earlier: there are cases where the AA would allow one merger by firms 1 and 2 , so that we would end up in the PI outcome, but where the merger is not profitable for the firms involved simply because of the output contraction involved; this happens for $(k, a)$ combinations in the "Contraction $S Q$ " region of Figure 8. We call this the contraction motive for not merging. Although this is a rather prosaic reason for abstaining from merger, we note that it does occur in our model solely because of the presence of an AA; as in the three-firm case, without an AA, there would be merger to monopoly for all parameter combinations. This is a case of firms not merging in order to get less concentration: when the AA will only allow a single merger anyway, the firms prefer no merger at all.
} 
place. As is evident from Figure 5 above, there is nothing (strictly) to gain from not merging, if no merger would be allowed anyway, with $S Q$ being the outcome.

(ii) Firm asymmetry. Figure 5 also illustrates clearly the importance of firm asymmetry for our findings. Symmetry, i.e., all three firms being of identical size, shows up in that Figure along the vertical $k=\frac{1}{3}$ line. The case of symmetry is not at all able to accommodate the pill-sweetening motive for not merging, since the AA is not affected by the sequence in which mergers occur when firms are of identical sizes. Pill sweetening only shows up for $k<\frac{1}{3}$, i.e., when firm 1 is smaller than the others, as indicated by Figure 5 .

The reason that pill sweetening can be a successful strategy when firm 1 is small is that, by having the two large firms merge, firm 1 makes AA more interested in allowing a further merger. This happens in cases where, in terms of welfare, $P I \succ C M \succ P O$, so that the AA will choose $C M$ over $P O$, and accept the merger, when firms 1 and 23 propose to merge at node 4 in Figure 2, but would choose $P I$ over $C M$, and reject, if firms 12 and 3 were to propose a merger at node 2. Such cases where $P I \succ C M \succ P O$, in the eyes of the AA, show up, on one hand, when firm asymmetry is such that the AA, among the two single-merger scenarios, prefers $P I$ to $P O$, i.e., when firm 1 is the smallest firm and $k<\frac{1}{3}$, since $P I$ then entails the smaller merger of the two; and, on the other hand, in an intermediate range of the market size, measured by $a$, where the AA might be interested in allowing an extra merger, so that $C M$ is between $P I$ and $P O$ in terms of welfare, rather than above or below both of them.

Symmetry can, however, accommodate the other two motives to not merge, albeit in a limited way. At $k=\frac{1}{3}$, there is a range of values of $a$ for which the choice for firm 1 is between outcomes $P I$ and $P O .{ }^{28}$ The AA is indifferent between the two outcomes in this borderline case of symmetry. But we find that firm 1 strictly prefers $P O$ to $P I$ because of the benefit accruing from free riding on the other two firms merging in outcome $P O$. This result is in line with previous work, such as Fridolfsson and Stennek (2005b). What does not come out of an analysis like theirs that is restricted to symmetry, though, is that firm 1 , by not merging, can free ride also in many cases where the AA would prefer that the firm be involved in a merger rather than it being on the outside of one, notably when $k<\frac{1}{3}$. Moreover, our analysis shows that a value of $k$ slightly above $\frac{1}{3}$ takes away the firm's strategic incentive not to merge, since now also the AA prefers $P O$ to $P I$.

Note that, while other authors analysing free riding, such as Fridolfsson and Stennek (2005b), simply assume that exactly one merger takes place, the range of parameter values for which exactly one merger occurs is here endogenously determined from an explicit consideration of the AA's objectives. When the market is big, the AA would not allow even a single merger and firm 1's incentive to free ride disappears. When the market is small, there is scope for more than one merger and the focus of firm 1 shifts to its benefit from multiple mergers. ${ }^{29}$

\footnotetext{
${ }^{28}$ That range is $\left[9+\frac{3}{5} \sqrt{105}, \frac{117}{7}+\frac{18}{7} \sqrt{37}\right] \approx[15.1,32.4]$.

${ }^{29}$ In another range of values of $a,\left[7+\sqrt{21}, 9+\frac{3}{5} \sqrt{105}\right) \approx[11.6,15.1)$, there will be com-
} 
(iii) The presence of an antitrust authority. This can be illustrated by repeating our analysis, with the difference that all decisions by the AA are taken away. The result of this exercise is presented in Figure 10 showing that, in case there is no AA who can veto mergers, the equilibrium outcome of the simplified game is trivial: complete monopolization of the market for all parameters. Thus, with no AA in place, there cannot be any pill sweetening.

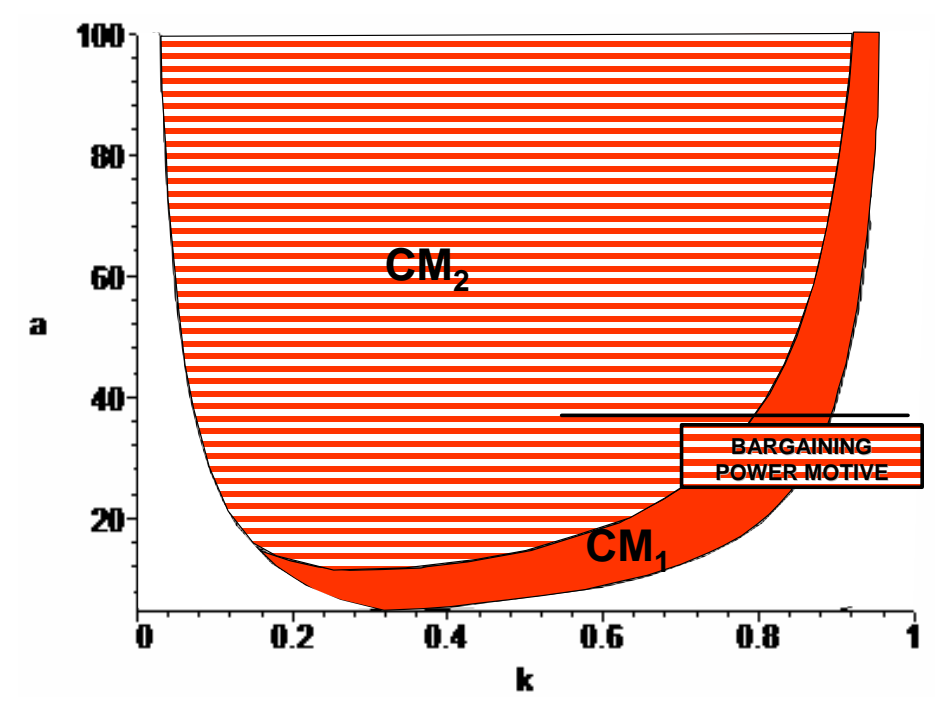

Figure 10. Equilibrium outcomes without an antitrust authority.

Still, firm 1 has the option to choose the equilibrium path through which such a market structure is formed. Thus, the bargaining-power motive not to merge immediately plays a role. If firm 1 were to join with another firm in the very beginning, then it would weaken its inside option in the ensuing bargaining to get the last firm to join (except if it itself is very large to start with), while after the merger between the other firms, firm 1 becomes an outsider and enjoys free-rider profits, strenghtening its bargaining position when joining the merger at a later stage. The outsider's position is stronger the bigger is the market, as it has more opportunities to expand output. Thus, unless firm 1 is very big ( $k$ high) or the market is very small ( $a$ low), firm 1 will decide to wait for the other two firms' merger. ${ }^{30}$

(iv) Economies or diseconomies of scale. Scale economies affect the AA's interest in allowing mergers: With diseconomies of scale, firm size is of less value

plete monopoly anyway for $k=\frac{1}{3}$, but firm 1 benefits from getting in late and so chooses not to merge at the first opportunity. This is the bargaining-power motive for not merging. Symmetry is not a restrictive assumption to make when discussing this motive. By introducing firm asymmetry, we are still able to show, though, that this motive is present, when an antitrust authority is around, both when firm 1 is relatively large $\left(k>\frac{1}{3}\right)$ and when it is relatively small $\left(k<\frac{1}{3}\right)$.

${ }^{30}$ The exact formula for the curve splitting the two $C M_{1}$ and $C M_{2}$ regions in Figure 7 is given in (A11) in the Appendix. 
to the antitrust authority. To see how this affects our analysis, we introduce a more general cost function than the one in (1). In particular, we now let a firm's cost be given by

$$
C\left(x_{i}\right)=\frac{1}{k_{i}}\left[c x_{i}+(1-c) \frac{x_{i}^{2}}{2}\right],
$$

where $c \geq 0$. If $c=1$, then we are back to the main case discussed above, with constant returns to scale. If $c \in[0,1)$, then there are decreasing returns to scale, and more so the lower is $c .^{31}$ We can also admit some values of $c$ greater than 1, giving rise to increasing returns to scale, as long as second-order conditions are satisfied. In order to illustrate the equilibrium outcomes when there are non-constant returns to scale in this way, we put $a=20$ and depict the outcome in $(k, c)$ space, restricting attention to combinations of $k$ and $c$ where second-order conditions are satisfied and all firms produce positive quantities in all outcomes of the merger game; see Figure 11. As is evident from that Figure, the pill-sweetening motive for not merging early disappears for sufficiently decreasing returns to scale, essentially because the antitrust authority's interest in accepting a merger later on disappears. As $c$ decreases, for values of $k$ a bit below symmetry at $\frac{1}{3}$, we see that, for moderately decreasing returns to scale, the antitrust authority will accept one merger only, and so firm 1 grasps the chance and merges immediately, while for even lower values of $c$, no merger at all will be accepted by the antitrust authority and so the industry stays in the status-quo outcome.

(v) The welfare standard. The weight put on firms' profits in the AA's objective function need to be sufficiently high in order to ensure the AA is interested in allowing mergers at the same time as firm 1 is interested in waiting in order to obtain more. A simple way of exploring the consequences of various assumptions on the AA's objective is to write the latter's objective function as

$$
U=\alpha C S+(1-\alpha) \Pi,
$$

where $\alpha \in[0,1]$. Here, $\alpha$ measures the weight put on consumer surplus relative to industry profit by the AA. In the analysis above, we put $\alpha=\frac{1}{2}$, which implies the total welfare standard. With $\alpha=1$, the AA would be applying the consumer welfare standard, while a value of $\alpha$ decreasing from 1 to $\frac{1}{2}$ would imply a steady movement from the consumer welfare standard towards the total welfare standard. As discussed in the Introduction, both US and EU merger policies entail an $\alpha$ at or close to 1 , although retrospective studies indicate that the US policy in practice is closer to the total welfare standard. Elsewhere, for example in Canada, the $\alpha$ is at or close to $\frac{1}{2}$. Allowing values of $\alpha$ less than $\frac{1}{2}$, as we do here, is merely for expositional reasons.

${ }^{31}$ At $c=0$, we have essentially the cost function used by Fumagalli and Vasconcelos (2009). 


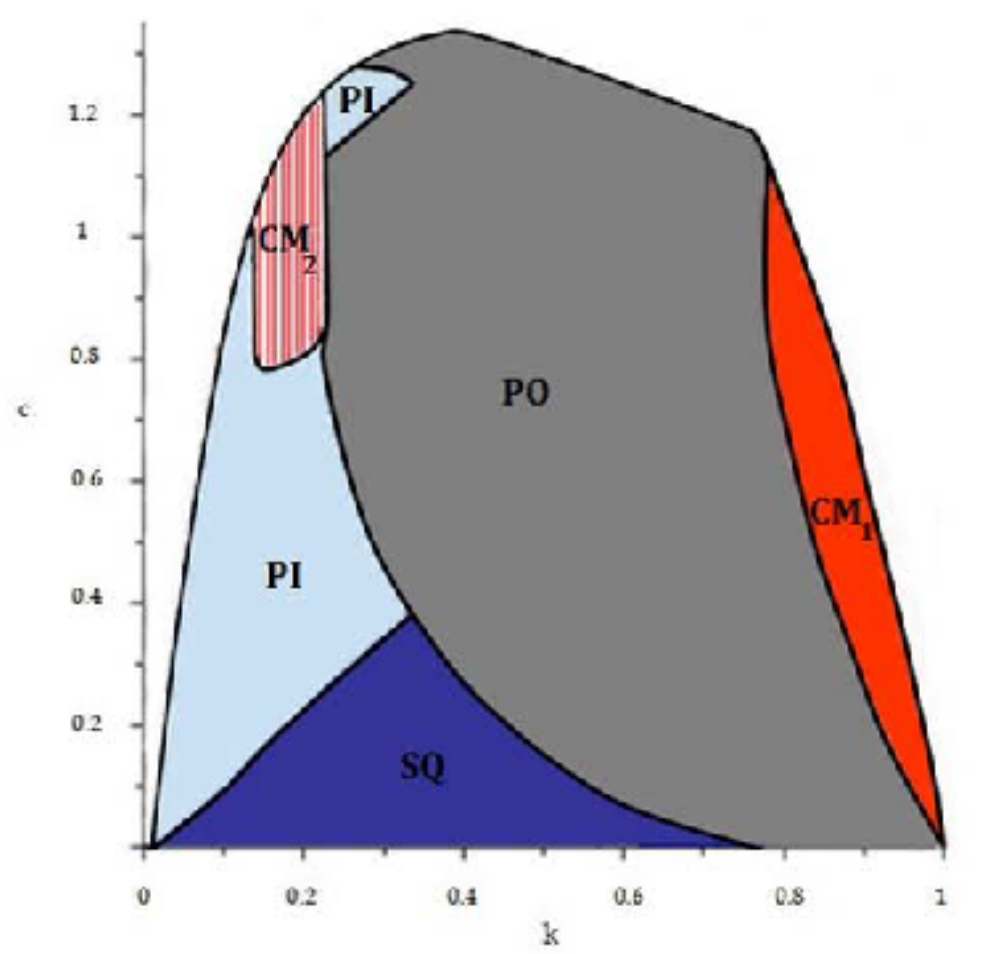

Figure 11. Equilibrium outcomes for different specifications of firms' costs.

When analyzing our model for different variations of the AA's objective, we find naturally that a stronger weight on consumer surplus makes the AA less interested in allowing mergers. When $\alpha$ is high, there is still some scope for the AA allowing mergers. However, this tends to happen only in cases where there are no incentives for firm 1 to pass up the opportunity to merge at stage 1. In Figure 12, we illustrate this for the case where market size is fixed at $a=20$. Thus, the Figure depicts various outcomes in $(k, \alpha)$ space. Note that the restriction that all firms be active in all possible outcomes of the merger game implies that we only consider cases where $k \in[0.12,0.81]$.

Figure 12 shows the presence of the three motives introduced above for a firm not to make a merger proposal at the first opportunity. As pointed out above, alignment of interests between the AA and the firms helps in obtaining our results: if, in the case of $a=20$ depicted in Figure 12, the AA were to apply the consumer welfare standard, with $\alpha=1$, no merger or, when firm 1 is big, only a merger not involving firm 1 would be allowed, deleting de facto any opportunity to strategically not propose a merger. Pill sweetening occurs when firm 1 is small for intermediate values of the AA's weight on consumer surplus. Note also how Figure 12 illustrates that also the free-riding and bargainingpower motives to not merge early disappear as we get close to $\alpha=1$. 


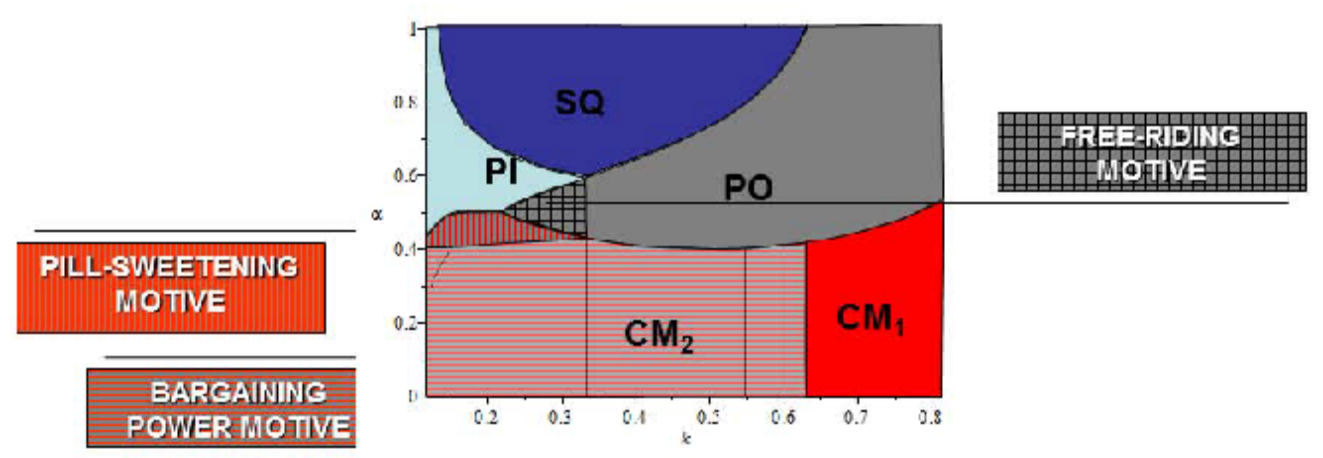

Figure 12. Equilibrium outcomes for different specifications of the welfare standard.

(vi) Legal restrictions on the antitrust authority's decisions. In the analysis so far, we assume that the AA is forward-looking when making its decisions. One might object to this that a merger proposal should be judged per se, a view that might put limits on the AA's ability to take into account all repercussions of its decision. However, we regard our assumption to be not too far from reality since, in practice, when an AA considers a merger proposal, it takes into account the possible development of the industry after that merger, such as increased/decreased chances for entry, for collusion - and for further mergers.

Nevertheless, with the view of checking for the robustness of our results with respect to this criticism, we consider here a variation of our model where AA's ability to make its decision based on the future development of the industry is restricted. The extreme way of modelling such restrictions is to assume that AA is myopic, i.e., that it takes its decision without considering that other mergers might follow. For example, at node $1 A$ of Figure 1, this myopic AA is comparing total welfare in $P I$ with that in $S Q$, ignoring the fact that, after the acceptance/rejection of the proposed merger between firms 1 and 2, further mergers might be proposed and accepted. ${ }^{32}$

Solving this modified version of our model, we find that our qualitative results are confirmed: there still are strategic reasons for not merging, and all three motives survive in the new model. Figure 13 depicts the equilibrium outcomes and the occurrence of strategic non merging of this new game.

Comparing this Figure with Figure 5 above, we find that a restricted AA implies a higher prevalence of $C M_{1}$, i.e., of complete monopoly following from

\footnotetext{
${ }^{32}$ There are alternative approaches to the modelling of myopia in the antitrust authority in the existing literature. First, Motta and Vasconcelos (2005) limit the discussion of the myopic antitrust authority to the case where a single merger is carried out, whereas we allow for two mergers to happen even when the antitrust authority thinks there will be only one. Secondly, Nocke and Whinston's (2010) model has product-market competition following each merger decision, which is different from both Motta and Vasconcelos (2005) and us. Thus, for them, myopia means for the antitrust authority to disregard any developments following the immediately subsequent product-market competition.
} 
firm 1 initially proposing a merger. The reason is that the AA, at node $1 A$, now simply compares $S Q$ and $P I$, not having in mind that a yes to a merger at this node may lead to a new merger proposal at node 2 , where the AA is more inclined to say yes to a merger than it is at node $1 A$, since it is only in the latter case that the AA can steer the industry over to the $P O$ outcome.

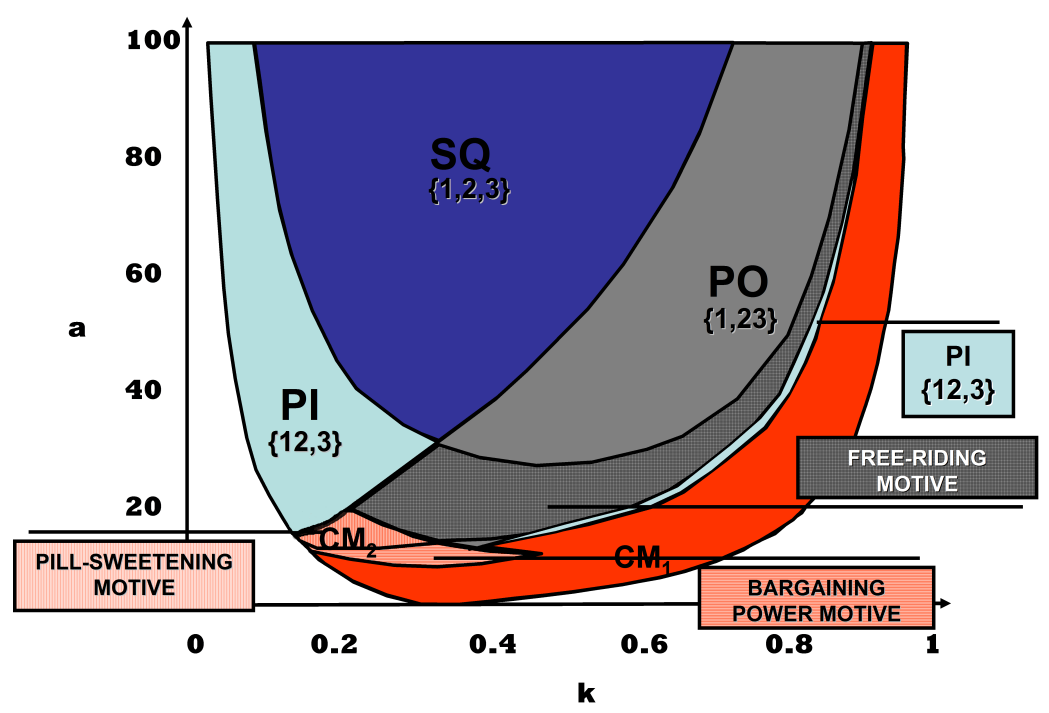

Figure 13. Equilibrium outcomes and strategic regions with a restricted antitrust authority.

Pill sweetening is still there when the AA is myopic. Its prevalence is slightly reduced, though. The reason is that, when the AA decides at node $3 A$ in Figure 1 whether or not to approve the merger between firms 2 and 3 , it is now unable to make a comparison between the eventual outcomes $S Q$ and $C M$ but is limited to comparing the outcomes $S Q$ and $P O$. This decreases the prevalence of the $C M$ outcome at node $3 A$, compared to the case of a forward-looking AA, and has in turn the consequence that firm 1 , when the $\mathrm{AA}$ is myopic, chooses to merge at node 1 , going for the $P I$ outcome, in some cases where it would pass up on the merger opportunity, going for pill sweetening by letting the two other firms merge first, if the AA were forward-looking.

We find a considerably increased prevalence of firms 1 and 2's not merging at node 1 because of free riding. This is because the AA at node $1 A$, as already discussed, now compares $P I$ to $S Q$ only, so that it is going to accept the merger also in cases where firm 1 is big, i.e., where $k>\frac{1}{3}$. This opens up both for firms 1 and 2 to merge when firm 1 is very big $(C M$ or $P I)$, and for firms 1 and 2 not to merge even if the merger would be accepted, because firm 1 prefers being an outsider $(P O)$.

The occurrence of a free-riding motive for not merging also for $k>\frac{1}{3}$ means that, in contrast to the case of a forward-looking AA, there are now motives 
for not merging in order to lower concentration since, for $k>\frac{1}{3}, P O$ implies a less concentrated industry than does $P I$; this happens because the myopic AA simply compares $P I$ with $S Q$ at node $1 A$, failing to realize that rejecting $P I$ would lead to $P O$, which both the AA and firm 1 would like to have when firm 1 is big.

Not surprisingly, weakening the AA this way leads essentially to equilibrium outcomes that are further away from the social optimum than in the standard model. ${ }^{33}$ Details are provided in Section A.4 in the Appendix.

(vii) Altering the move sequence. Suppose we let one of the other two firms, the equal-sized firms 2 and 3, make the first decision whether or not to merge at the first stage of the game. Say firm 2 is the first-mover. Since it has two potential merger partners of different sizes, firm 2 has three alternatives to choose from: \{Merge with firm 1; Merge with firm 3; No merger\}. If firm 2 now chooses not to merge, this ends the game. The two possibilities of a first merger have been considered already at the first stage: a merger between two equal-sized firms (firms 2 and 3) and a merger between two different-sized firms (firm 1 and one of the others). This move sequence therefore does not make us able to discuss a firm's incentive not to merge for strategic reasons: when the first movers choose not to merge, it is simply because a merger at node 1 is unprofitable.

(viii) Alternative ways to model firm asymmetry. An alternative model of firm asymmetry is the one used by Barros (1998). Instead of using the notion of a factor that is in fixed total supply in the industry, as we do here, he simply posits a Cournot oligopoly with constant but asymmetric marginal costs. ${ }^{34}$ In line with his approach, we could have assumed three firms, one with a constant marginal cost $c>0$ and the other two with an identical and constant marginal cost equal to $c+\delta$, where $\delta \in(-c, c)$. In a merger between two firms with different costs, the merged entity makes use of the more efficient technology and therefore gets a constant marginal cost equal to $\min \{c, c+\delta\}$. One problem with this approach, in relation to the issues we discuss here, is the inability to distinguish between the two cases $P I$ and $P O$. In both cases, the industry consists of two firms with different costs, one with marginal cost $c$ and the other with marginal cost $c+\delta .{ }^{35}$

(ix) Paying for the right to merge. It can be argued that our results on firm 1's motivation to pass up on its merger opportunity stem from the firm not getting enough out of its potential popularity as a merging partner with the current structure of the merger game. If each of the two identical firms 2

\footnotetext{
${ }^{33} \mathrm{~A}$ little caveat is in order here, since the prevalence of pill sweetening is slightly reduced, as just discussed.

${ }^{34}$ Barros finds, in a three-firm oligopoly where merger to monopoly is not allowed, that a big asymmetry leads to a merger between the two most efficient firms while a medium-sized asymmetry leads to a merger between the most and the least efficient firm.

${ }^{35}$ One could, of course, try to take the analysis a step further by letting all three firms have different marginal costs. Along the lines of Barros (1998), again, one could for example think of letting the three firms have constant marginal costs equal to $c_{1}=c, c_{2}=c+\delta$, and $c_{3}=c-\delta$, where now $\delta \in(0, c)$. This would, however, complicate the analysis a lot, and there would not be any obvious choice of a move sequence.
} 
and 3 would prefer merging immediately with firm 1 to waiting until the two firms' chance comes to merge with each other later on, then one would think that firm 1 should be able to play its two suitors up against each other. One way to accommodate this would be to replace firm 1's merger with firm 2 at node 1 with an auction between firms 2 and 3 for the right to merge with firm 1. We have experimented with a set-up in the spirit of this alternative, in which the Nash bargaining between firms 1 and 2 in the merger process at node 1 is substituted with firm 1 making a take-it-or-leave-it offer to firm 2 while all other merger processes at later nodes are kept as before. Although this change gives firm 1 a larger gain from merging immediately, it turns out that our results stand essentially unaltered. ${ }^{36}$

\section{Conclusion}

While granting permissions is a wide-spread task for government agencies, merger policy is a special kind of permission granting in that the externality exerted on other firms by one firm, or rather group of firms, obtaining a permission is not necessarily negative. This causes disincentives to seek an early permission - not only in order to free ride on firms getting permission, but also, as we have shown here, in order to get the authorities eventually to grant more permissions.

In order to get a grasp on this issue, we have in this paper introduced a simple model of sequential mergers, enabling us to study firms' incentives to pass up opportunities to merge. In particular, we point out what we call the pill-sweetening motive for not merging early. This motive occurs in cases where the number of mergers the antitrust authority is willing to accept depends on the order of merger proposals. By holding back its own merger and letting other combinations form first, a firm may get more mergers through acceptance of the antitrust authority. As our analysis shows, this happens only when the firm is smaller than the others. Thus, an empirical implication of our model is that large mergers happen before small ones.

Among the crucial assumptions of our model, it is worth pointing out two: size asymmetry among firms in the industry; and some alignment of interest between firms and the antitrust authorities. Both of them have policy implications. First, while it has been pointed out earlier how a merger leading to a more symmetric industry also leads to a more collusion-prone industry (e.g., Vasconcelos, 2005), we see here that more symmetry may also reduce firms' incentives to strategically hold back merger proposals. Secondly, the role played by the antitrust authority's objectives has implications for the current discussions on the best objective to impose on a government's competition agency. ${ }^{37}$ In line with other contributions in the literature, we find, although in a simple model, that an antitrust authority maximizing total welfare leads to strategic behav-

\footnotetext{
${ }^{36}$ The incidence of pill sweetening is not affected by this. The only change is that the incidence of the bargaining-power motive for not merging is slightly reduced.

${ }^{37}$ See Farrell and Katz (2006) for an overview of the literature on welfare standards to use in antitrust.
} 
iour among firms - in this case strategically holding back on merger proposals - that is counter to the interests of society and that does not show up when the antitrust authority is strongly consumer biased. As such, our analysis provides further arguments for government to insist on the consumer welfare standard in assessments of merger proposals.

\section{A Appendix}

\section{A.1 Some notation}

In Sections A.2 and A.3 of this Appendix, we provide the complete solution of the model. In order to do this, we introduce some notation that might seem a bit elaborate for this three-firm model, but it has been chosen in order to facilitate extensions to cases with more than three firms. ${ }^{38}$

Recall that the set of possible outcomes of the merger game is

$$
\Xi:=\{S Q, P O, P I, C M\} .
$$

In order to ease notation, we will sometimes need to express an outcome by a single letter: $Q=S Q ; O=P O ; I=P I ; C=C M$; and $\Xi=\{Q, O, I, C\}$. Furthermore, we denote the set of decision nodes in the merger game by $N:=$ $\{1,1 A, \ldots, 4,4 A\}$; see Figure 1 in the text.

The model has two exogenous parameters: $a$, which measures market size; and $k$, which measures firm asymmetry. As noted in Section 2, we restrict attention to those combinations $(k, a)$ for which all existing firms produce positive quantities in all the four outcomes outlined above. We do this by, for every $\xi \in \Xi$ and every $k \in(0,1)$, restricting $a$ such that $a \geq \underline{a}^{\xi}(k)$, where, for each $\xi \in \Xi, \underline{a}^{\xi}(k)$ is described in the next Section. These outcome-wise restrictions can be summarized in the restriction

$$
a \geq \underline{a}(k):=\max \left\{\underline{a}^{S Q}(k), \ldots, \underline{a}^{C M}(k)\right\} .
$$

In the following, our attention is thus limited to parameter combinations $(k, a) \in$ $Z:=\{(k, a) \mid a \geq \underline{a}(k)\}$.

Our aim is, for each combination $(k, a) \in Z$ of market size and firm asymmetry, to find the corresponding equilibrium outcome. We do this through backward induction by first solving the product-market game in each of the four situations. Thereafter, we proceed by looking at each node $n \in N$ to determine, for each $(k, a) \in Z$, what the eventual outcome of the merger game is; i.e., we are looking for an outcome partition $\Omega^{n}$ of $Z$ at each node, where $\Omega^{n}:=\left\{Z_{\xi}^{n}, Z_{\iota}^{n}, \ldots\right\}$, and $Z_{\xi}^{n}$ consists of all $(k, a) \in Z$ such that the outcome of the merger subgame starting at node $n \in N$ is $\xi \in \Xi$. The equilibrium outcome of the whole merger game then corresponds to $\Omega^{1}$, the outcome partition at node 1.

\footnotetext{
${ }^{38}$ See the online appendix for an analysis of the four-firm case.
} 
Let $M(n)$ be the entity that makes a decision at decision node $n \in N$. $M(n)$ compares the possible outcomes that can follow each of its decisions. Let $\Gamma^{n} \subseteq \Xi$ denote the set of outcomes that can occur after node $n$. For example, at node $4 A$ in Figure 1, $\Gamma^{4 A}=\{P O, C M\}$. Denote by $V_{\xi \iota}^{n} \subset Z$ the relevant region of the parameter space at node $n \in N$ for the comparison between outcomes $\xi, \iota \in \Gamma^{n}$; that is, $V_{\xi \iota}^{n}$ is the set of combinations $(k, a)$ such that taking one of the feasible actions at node $n$ would lead to outcome $\xi$ and taking another one would lead to outcome $\iota$. Define $\xi Y_{\iota}^{m} \subset Z$ as the set of combinations for which decision maker $m$ prefers outcome $\xi$ to outcome $\iota$, where $\xi, \iota \in \Xi$. Let the decision maker at node $n$ be denoted $m=M(n)$. If $n$ is a merger node, then $m$ is a pair of firms choosing whether or not to propose a merger. If $n$ is an AA node, then $m$ is the AA. We express $Z_{\xi}^{n}$, introduced in the previous paragraph, as the collection of all parameter combinations for which outcome $\xi$ is preferred by the decision maker $M(n)$ at node $n$ to another outcome in the relevant region of comparison between the two outcomes; to be precise:

$$
Z_{\xi}^{n}:=\cup_{\iota \in \Gamma^{n}, \iota \neq \xi}\left(V_{\xi \iota}^{n} \cap{ }_{\xi} Y_{\iota}^{M(n)}\right), n \in N, \xi \in \Gamma^{n} .
$$

Let $\widetilde{N}$ denote the set of end nodes of the merger game. End nodes are not decision nodes, and outcome partitions at end nodes are degenerate: if the merger game ends in outcome $\xi \in \Xi$ at end node $\widetilde{n} \in \widetilde{N}$, then the outcome partition of that end node is $\left\{Z_{\xi}^{\tilde{n}}\right\}=\{Z\}$. The relevant region at a decision node can thus be constructed recursively through the outcome partitions of the node's immediate successors:

$$
V_{\xi \iota}^{n}:=\left[\cup_{l \in I^{n} \cap \Phi_{\xi}} Z_{\xi}^{l}\right] \cap\left[\cup_{l \in I^{n} \cap \Phi_{\iota}} Z_{\iota}^{h}\right],
$$

where $I^{n}$ is the set of immediate successor nodes of node $n$ and

$$
\Phi_{\xi}:=\left\{n \in N \cup \tilde{N} \mid Z_{\xi}^{n} \neq \varnothing\right\}
$$

is the set of nodes from which outcome $\xi$ is a possible outcome. At every decision node in the present model, however, $I^{n}$ consists of two nodes, so that the expression simplifies to:

$$
V_{\xi \iota}^{n}=Z_{\xi}^{l} \cap Z_{\iota}^{h},
$$

where $l, h \in I^{n}$, and $l \neq h$, such that $l \in \Phi_{\xi}$ and $h \in \Phi_{\iota}{ }^{39}$

\section{A.2 Product-market competition}

The outcome of the quantity competition depends on which situation we are in. Below, we go through the four different situations that may occur in order to characterize the equilibrium in each of them.

\footnotetext{
${ }^{39}$ See the analysis of the four-firm case, in the online appendix, for a case where $I^{n}$ may consist of more than two nodes.
} 
Status Quo (SQ): $\{\mathbf{1 , 2 , 3}\}$ In this situation, one firm of size $k$ and two firms each of size $\frac{1-k}{2}$ compete. The first-order condition of firm 1 is: $a-X-x_{1}-\frac{1}{k}=$ 0 , while the first-order condition of firm $s \in\{2,3\}$ is: $a-X-x_{s}-\frac{2}{1-k}=0$. Imposing symmetry on the identical firms 2 and 3 , we can write these conditions as: $2 x_{1}+2 x_{s}=a-\frac{1}{k}$, and $x_{1}+3 x_{s}=a-\frac{2}{1-k}$. Solving this system, we have

$$
\begin{aligned}
x_{1}^{S Q} & =\frac{1}{4}\left(a-\frac{3-7 k}{k(1-k)}\right), \\
x_{2}^{S Q} & =x_{3}^{S Q}=\frac{1}{4}\left(a-\frac{5 k-1}{k(1-k)}\right),
\end{aligned}
$$

so that having non-negative quantities from all three firms requires $\underline{a}^{S Q}(k):=$ $\max \left\{\frac{3-7 k}{k(1-k)}, \frac{5 k-1}{k(1-k)}\right\}$, and total quantity is

$$
X^{S Q}=\frac{1}{4}\left(3 a-\frac{3 k+1}{k(1-k)}\right) .
$$

Partial Out (PO): $\{\mathbf{1 , 2 3}\}$ We have two firms: firm 1 of size $k$ and firm 23 of size $1-k$. The first-order conditions of the firms are: $a-X-x_{1}-\frac{1}{k}=0$; and $a-X-x_{23}-\frac{1}{1-k}=0$. Rewriting, we have: $2 x_{1}+x_{23}=a-\frac{1}{k} ; x_{1}+2 x_{23}=a-\frac{1}{1-k}$. Solving this system, we have

$$
\begin{aligned}
x_{1}^{P O} & =\frac{1}{3}\left(a-\frac{2-3 k}{k(1-k)}\right), \\
x_{23}^{P O} & =\frac{1}{3}\left(a-\frac{3 k-1}{k(1-k)}\right) .
\end{aligned}
$$

Thus, $\underline{a}^{P O}(k):=\max \left\{\frac{2-3 k}{k(1-k)}, \frac{3 k-1}{k(1-k)}\right\}$. Total quantity is

$$
X^{P O}=\frac{1}{3}\left(2 a-\frac{1}{k(1-k)}\right) .
$$

Partial In (PI): $\{\mathbf{1 2 , 3}\}$ We have one big firm, 12, of size $k+\frac{1-k}{2}=\frac{1+k}{2}$ and one small firm, firm 3 , of size $\frac{1-k}{2}$. The first-order condition of firm 12 is: $a-X-x_{12}-\frac{2}{1+k}=0$, while the first-order condition of firm 3 is: $a-X-x_{3}-$ $\frac{2}{1-k}=0$. We rewrite to obtain: $2 x_{12}+x_{3}=a-\frac{2}{1+k} ; x_{12}+2 x_{3}=a-\frac{2}{1-k}$. Solving the system, we have

$$
\begin{aligned}
& x_{12}^{P I}=\frac{1}{3}\left(a-\frac{2(1-3 k)}{1-k^{2}}\right), \\
& x_{3}^{P I}=\frac{1}{3}\left(a-\frac{2(1+3 k)}{1-k^{2}}\right),
\end{aligned}
$$

so that non-negative quantities require $a \geq \underline{a}^{P I}(k):=\max \left\{\frac{2(1-3 k)}{1-k^{2}}, \frac{2(1+3 k)}{1-k^{2}}\right\}$. Total quantity is

$$
X^{P I}=\frac{2}{3}\left(a-\frac{2}{1-k^{2}}\right) .
$$


Complete Monopoly (CM): $\{\mathbf{1 2 3}\} \quad$ In complete monopoly, there is a single firm, 123, whose first-order condition is: $a-2 x_{123}-1=0$. In other words,

$$
X^{C M}=x_{123}^{C M}=\frac{a-1}{2},
$$

so that $\underline{a}^{C M}(k):=1$.

Based on the above, we can now be specific about the function $\underline{a}(k)$, which restricts the set $Z$ of combinations $(k, a)$ of interest and is given by the following piecewise relationship:

$$
\underline{a}(k):=\left\{\begin{array}{l}
\underline{a}^{S Q}(k)=\frac{3-7 k}{k(1-k)}, \text { if } k \in\left(0, \frac{1}{4}\right) ; \\
\underline{a}^{P O}(k)=\frac{2-3 k}{k(1-k)}, \text { if } k \in\left[\frac{1}{4}, \frac{1}{3}\right) ; \\
\underline{a}^{P I}(k)=\frac{2(1+3 k)}{1-k^{2}}, \text { if } k \in\left[\frac{1}{3}, 1\right) .
\end{array}\right.
$$

\section{A.3 The merger game}

In order to solve the game, we proceed by backward induction. Consider, therefore, node $4 A$ in Figure 1, where AA decides whether to approve a merger between firms 1 and 23. If AA says no to the merger, then the merger game stops in the $P O$ situation, whereas a yes leads to $C M$; in other words, $\Gamma^{4 A}=\{P O, C M\}$. The two immediate successors to node $4 A$ are both end nodes, implying that $V_{C P}^{4 A}=Z$. AA compares $T W$ in the two outcomes and approves the merger if and only if ${ }^{40}$

$$
(k, a) \in{ }_{C} Y_{O}^{A}:=\left\{(k, a) \in Z \mid a \leq a_{C O}^{A}(k)\right\},
$$

where

$$
a_{C O}^{A}(k):=\frac{27 k^{2}-27 k+16+6 \sqrt{24 k^{4}-48 k^{3}+28 k^{2}-4 k+1}}{5 k(1-k)}
$$

Intuitively, the merger is approved if the market is so small that there is no room for two firms in the market. Thus, the outcome partition at node $4 A$ is $\Omega^{4 A}=\left\{Z_{C M}^{4 A}, Z_{P O}^{4 A}\right\}$, where $Z_{C M}^{4 A}=V_{C O}^{4 A} \cap{ }_{C} Y_{O}^{A}={ }_{C} Y_{O}^{A}$, and $Z_{P O}^{4 A}=Z \backslash Z_{C M}^{4 A}$.

At node 4 , firms 1 and 23 decide whether or not to propose a merger. Possible outcomes are $\Gamma^{4}=\Gamma^{4 A}=\{P O, C M\}$. The firms prefer to merge if

$$
\pi_{1}^{C M_{2}} \geq \pi_{1}^{P O} .
$$

Since

$$
\pi_{1}^{C M_{2}}=\frac{1}{2}\left(\pi_{123}^{C M}+\pi_{1}^{P O}-\pi_{23}^{P O}\right)
$$

the condition in (A3) amounts to

$$
\pi_{123}^{C M} \geq \pi_{1}^{P O}+\pi_{23}^{P O}
$$

\footnotetext{
${ }^{40}$ There are two solutions to the equation $a=a_{C O}^{A}(k)$. We report here only the one that is at least partly within $Z$. The other one is always outside $Z$ and therefore irrelevant for our analysis and not reported. The same consideration holds for later cases.
} 
in other words: firms 1 and 23 prefer to merge exactly when the profit of the merged unit is larger than what the two firms can get separately. The condition holds for all $(k, a) \in Z$, so ${ }_{C} Y_{O}^{1}=Z$. Thus, $\Omega^{4}=\Omega^{4 A}$, and a merger is proposed at node 4 if and only if (A1) holds.

At node $3 A$, the AA decides whether to approve a merger between firms 2 and 3. Possible outcomes are $\Gamma^{3 A}=\{C M, P O, S Q\}$. In particular, if the AA says no, then the merger game ends in an $S Q$ outcome; if it says yes, then the game ends in $C M$ if (A1) holds, in $P O$ otherwise. Consider first the comparison between $C M$ and $S Q$. The relevant region is $V_{C Q}^{3 A}=Z_{C M}^{4}=Z_{C M}^{4 A}$. The AA prefers $C M$ to $S Q$ if and only if $(k, a) \in{ }_{C} Y_{Q}^{A}:=\left\{(k, a) \in Z \mid a \leq a_{C Q}^{A}(k)\right\}$, where

$$
a_{C Q}^{A}(k):=\frac{12 k^{2}+3 k+5+2 \sqrt{45 k^{4}-114 k^{2}+96 k-11}}{3 k(1-k)}
$$

Consider next the comparison between $P O$ and $S Q$. The relevant region is $V_{O Q}^{3 A}=Z_{P O}^{4}=Z_{P O}^{4 A}$. The AA prefers $P O$ to $S Q$ if $(k, a) \in{ }_{O} Y_{Q}^{A}:=$ $\left\{(k, a) \in Z \mid a \leq a_{O Q}^{A}(k)\right\}$, where

$$
a_{O Q}^{A}(k):=\frac{135 k-19+12 \sqrt{64 k^{2}-12 k+1}}{7 k(1-k)} .
$$

Putting this together, we see that $\Omega^{3 A}=\left\{Z_{C M}^{3 A}, Z_{P O}^{3 A}, Z_{S Q}^{3 A}\right\}$; see Figure A1.

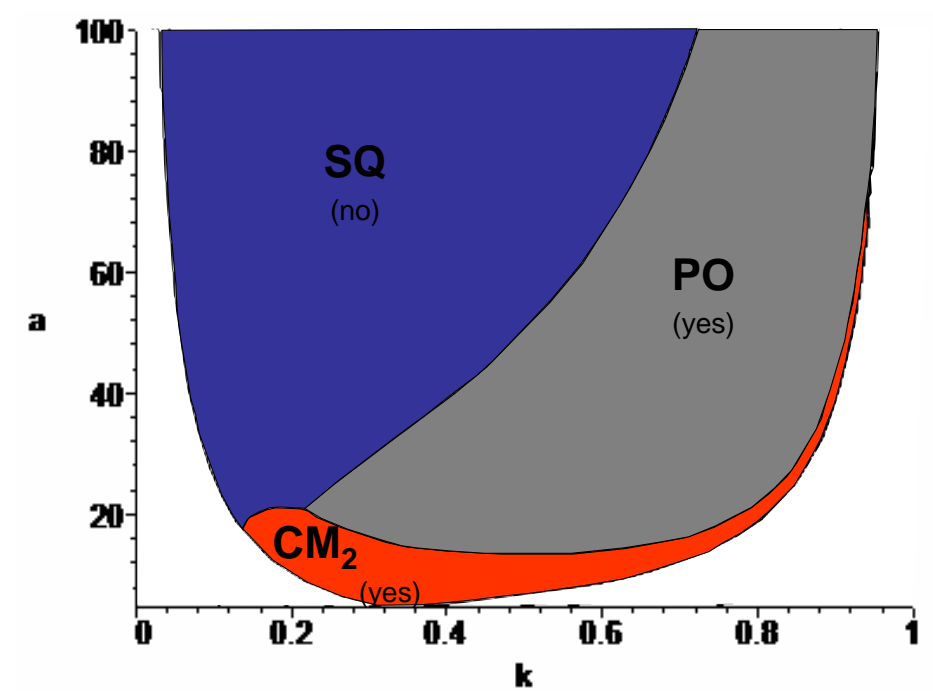

Figure A1. Outcomes at node $3 A$.

Here, $Z_{C M}^{3 A}=\left\{(k, a) \in Z \mid a \leq \min \left\{a_{C Q}^{A}(k), a_{C O}^{A}(k)\right\}\right\}:$ when the market, measured by $a$, is small, both this merger and the next one (to be proposed at node 4) are accepted by the AA, and the merger game ends in a $C M$ outcome; $Z_{P O}^{3 A}=\left\{(k, a) \in Z \mid a_{C O}^{A}(k)<a \leq a_{O Q}^{A}(k)\right\}$ : when firm 1 is big ( $k$ is large), the AA prefers balancing it by accepting the merger between the two small firms 
2 and 3 here at node $3 A$ but will not allow a merger to $C M$ later on at node $4 A$; and finally $Z_{S Q}^{3 A}=\left\{(k, a) \in Z \mid a>\max \left\{a_{C Q}^{A}(k), a_{O Q}^{A}(k)\right\}\right\}$ : when the market is large, there is no reason for the AA to allow any merger at all.

At node 3, no merger has taken place so far in the game when firms 2 and 3 consider whether or not to merge. We have $\Gamma^{3}=\left\{C M_{2}, P O, S Q\right\}$ : In parallel to node $3 A$ discussed above, we need to compare $S Q$ with the outcomes $C M$ and $P O$, but this time from the perspective of firms 2 and 3 rather than that of the AA; note that we now need to be explicit on which kind of complete monopoly is obtained. Consider first the comparison between $C M_{2}$ and $S Q$. The relevant region is $V_{C Q}^{3}=Z_{C M}^{3 A}$. In order to find firm 2's share of the profit in the completely monopolized industry, $\pi_{2}^{C M_{2}}$, we note that firms 2 and 3 , if they merge, will eventually end up in the $C M$ outcome. Thus, for firm 2 at node 3 , merger is preferable to no merger if

$$
\pi_{2}^{C M_{2}}=\frac{1}{2}\left(\pi_{23}^{C M}+\pi_{2}^{S Q}-\pi_{3}^{S Q}\right) \geq \pi_{2}^{S Q}
$$

Since firms 2 and 3 are identical, we have $\pi_{2}^{S Q}=\pi_{3}^{S Q}$. Using this and inserting from

$$
\pi_{23}^{C M}=\frac{1}{2}\left(\pi_{123}^{C M}+\pi_{23}^{P O}-\pi_{1}^{P O}\right)
$$

we can write (A6) as

$$
\frac{1}{4}\left(\pi_{123}^{C M}+\pi_{23}^{P O}-\pi_{1}^{P O}\right) \geq \pi_{2}^{S Q} .
$$

This leads to the finding that firms 2 and 3 , in the relevant region, always prefer $C M_{2}$ to $S Q$. In the comparison between $P O$ and $S Q$, where $V_{O Q}^{3}=Z_{P O}^{3 A}$, we find similarly that also $P O$ is preferred to $S Q$ for any $(k, a) \in Z_{P O}^{3 A}$. The conclusion for node 3 , therefore, is that a merger is proposed whenever it will be accepted at node $3 A$, i.e., $\Omega^{3}=\Omega^{3 A}$.

Next, we move to node $2 A$, where the AA decides whether to approve a merger between firms 12 and 3 . The choice is essentially between outcomes $P I$ and $C M$, i.e., $\Gamma^{2 A}=\{P I, C M\}$, and $V_{C B}^{2 A}=Z$. We find that the AA prefers $C M$ to $P I$ if and only if $(k, a) \in{ }_{C} Y_{I}^{A}:=\left\{(k, a) \in Z \mid a \leq a_{C I}^{A}(k)\right\}$, where

$$
a_{C I}^{A}(k):=\frac{27 k^{2}+37+12 \sqrt{6 k^{4}-8 k^{2}+6}}{5(k+1)(1-k)} .
$$

This gives us $\Omega^{2 A}=\left\{Z_{C M}^{2 A}, Z_{P I}^{2 A}\right\}$; see Figure A2.

Complete monopoly is fine with the AA if the market is small or if firm 1, and therefore even more so the merged entity 12 , are anyway so big that the outside firm 3 does not make up any reasonable balance.

At node 2, firms 12 and 3 decide whether or not to join up to create a complete monopoly. The comparison is also here between $C M$ and $P I: \Gamma^{2}=$ $\{P I, C M\}$, and $V_{C I}^{2}=Z$. We find that a merger is always preferable, and so a merger is proposed whenever it will be accepted: $\Omega^{2}=\Omega^{2 A}$. 
At node $1 A$, the AA says yes or no to the merger between firms 1 and 2. If it says no, then the game moves to node 3 in Figure 1. If it says yes, then the game moves to node 2 . Thus, all outcomes are possible at this node: $\Gamma^{1 A}=\{C M, P I, P O, S Q\}$. The two outcomes $P O$ and $S Q$ can only occur if the AA says no and moves the game to node 3 . Therefore, there is no need to discuss the comparison between the two at node $1 A$. In the comparison between $C M$ and $P O$, we note that $V_{C O}^{1 A}=Z_{C M}^{2} \cap Z_{P O}^{3}$. Thus, $V_{C O}^{1 A} \cap{ }_{C} Y_{O}^{A}=\varnothing$; whenever the comparison between $C M$ and $P O$ is relevant at node $1 A$, the AA prefers $P O$. In the comparison between $P O$ and $P I$, the relevant region is $V_{O I}^{1 A}=Z_{P I}^{2} \cap Z_{P O}^{3}$. Note that, from the AA's point of view, the two outcomes $P O$ and $P I$ are identical when $k=\frac{1}{3}$, in which case the industry consists of one firm of size $\frac{2}{3}$ (firm 12 in the case of $P I$ and firm 23 in the case of $P O$ ) and one firm of size $\frac{1}{3}$ (firm 3 in the case of $P I$ and firm 1 in the case of $P O$ ). With $k$ going slightly below $\frac{1}{3}$, the big firm gets bigger in the case of $P O$ and smaller in the case of $P I$. Thus, the AA prefers $P I$ to $P O$ whenever $k<\frac{1}{3}:{ }_{I} Y_{O}^{A}:=\left\{(k, a) \in Z \mid k<\frac{1}{3}\right\}$.

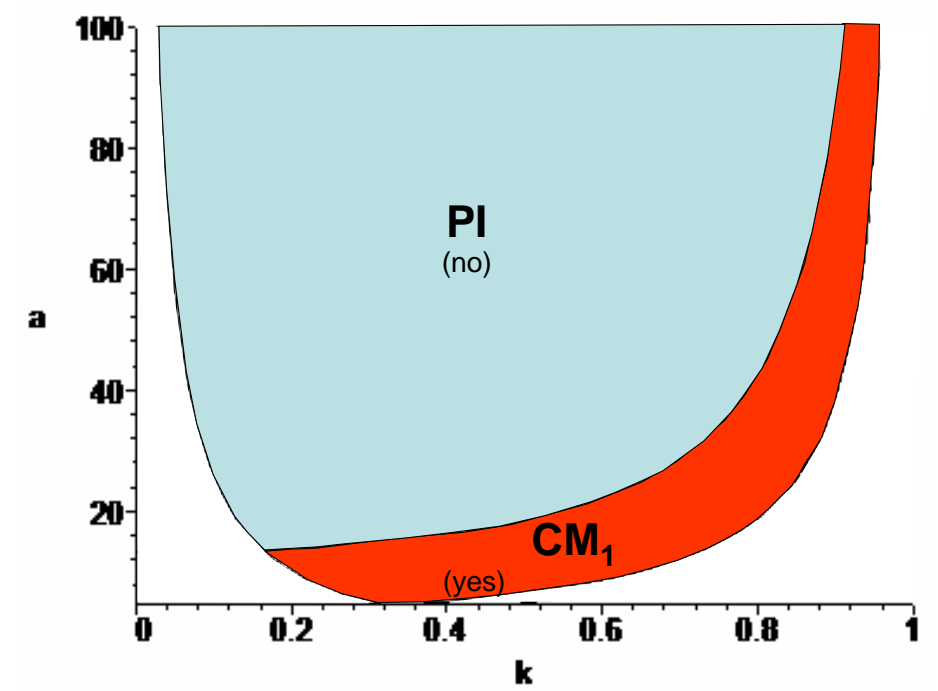

Figure A2. Outcomes at node $2 A$.

In the comparison between $P I$ and $S Q$, the relevant region is $V_{I Q}^{1 A}=Z_{S Q}^{3}$. We have that the AA prefers $P I$ to $S Q$ if and only if $(k, a) \in{ }_{I} Y_{Q}^{A}:=$ $\left\{(k, a) \in Z \mid a \leq a_{I Q}^{A}(k)\right\}$, where

$$
a_{I Q}^{A}(k):=\frac{135 k^{2}-76 k+45+24 \sqrt{37 k^{4}-68 k^{3}+38 k^{2}-4 k+1}}{7 k(k+1)(1-k)} .
$$

Finally, in the comparison between $P I$ and $C M$, there is a possibility for the AA to obtain $C M$ in stead of $P I$ when $(k, a) \in V_{C I}^{1 A}=Z_{P I}^{2} \cap Z_{C M}^{3}$. However, for any $(k, a) \in V_{C I}^{1 A}$, the AA prefers $P I$ to $C M$.

Our findings for node $1 A$ are summarized in Figure A3. As is evident from that Figure, the AA says no to the merger proposal in order to obtain either $S Q$ or $P O$. Saying no means moving the game over to node 3 . 
The AA prefers $S Q$ when the market is large (high $a$ ) and the firms not very asymmetric ( $k$ not very small or very large): $Z_{S Q}^{1 A}=Z_{S Q}^{3} \backslash{ }_{I} Y_{Q}^{A}$. For intermediate market sizes or for a very small firm 1 ( $k$ small), the AA prefers $P I: Z_{P I}^{1 A}=\left\{(k, a) \in\left(Z_{P I}^{2} \cap{ }_{I} Y_{Q}^{A}\right) \mid k<\frac{1}{3}\right\}$. For intermediate market sizes or for a big firm 1 ( $k$ large), the AA prefers $P O: Z_{P O}^{1 A}=\left\{(k, a) \in Z_{P O}^{3} \mid k \geq \frac{1}{3}\right\}$. Finally, the AA prefers $C M$ when the market is small: $Z_{C M}^{1 A}=Z_{C M}^{2} \cap Z_{C M}^{3}$.

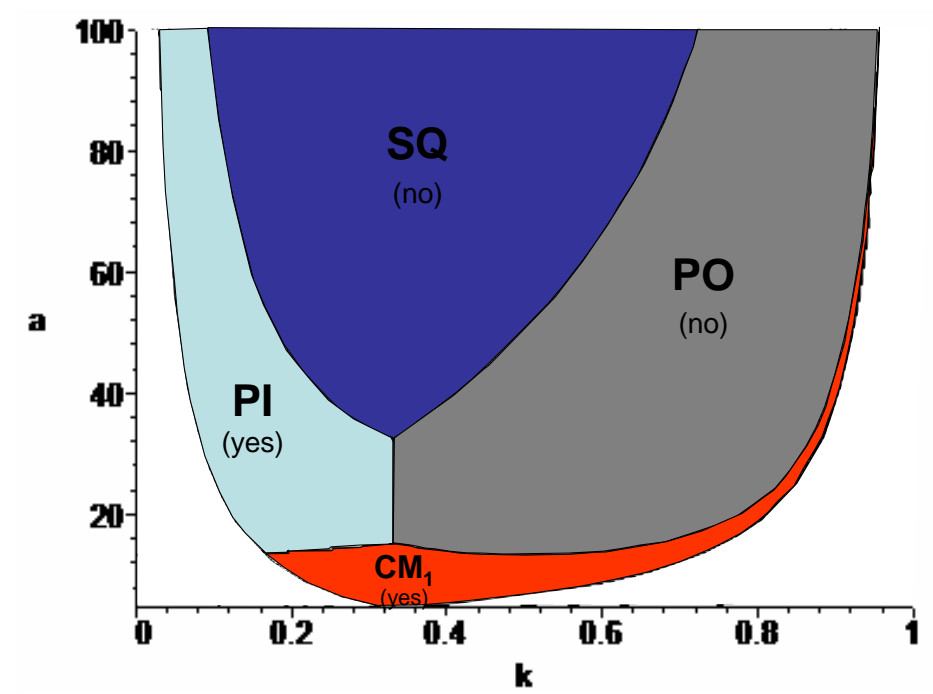

Figure A3. Outcomes at node $1 A$.

At node 1, firms 1 and 2 decide whether or not to merge. A merger proposal would move the game to node $1 A$, where the AA decides whether or not to accept, whereas a decision not to merge would move the game to node 3 , where firms 2 and 3 decides whether or not to merge. The first thing to note is that firm 1's share of the monopolist's profit in $C M$ differs between $C M_{1}$ and $C M_{2}$. The crucial question is firm 1's incentive to take part in the node- 1 merger. Whereas firm 1's share of the monopoly profit in $C M_{2}$ is

$$
\pi_{1}^{C M_{2}}=\frac{1}{2}\left(\pi_{123}^{C M}+\pi_{1}^{P O}-\pi_{23}^{P O}\right)
$$

as noted in (A4) above, its share in $C M_{1}$ is found by first finding 12's share in the merger taking place at node 2 ,

$$
\pi_{12}^{C M_{1}}=\frac{1}{2}\left(\pi_{123}^{C M}+\pi_{12}^{P I}-\pi_{3}^{P I}\right) .
$$

At node 1, firm 1's share in the merged unit's profit, when the final outcome is complete monopoly, is

$$
\pi_{1}^{C M_{1}}=\frac{1}{2}\left(\pi_{12}^{C M_{1}}+\pi_{1}^{S Q}-\pi_{2}^{S Q}\right) .
$$


Now, comparing $\pi_{1}^{C M_{1}}$ in (A10) and $\pi_{1}^{C M_{2}}$ in (A4), we find that, when $(k, a) \in$ $Z_{C M}^{1 A} \cap Z_{C M}^{3}$, so that the final outcome is anyway $C M$, firm 1 prefers not to merge immediately if and only if $\pi_{1}^{C M_{2}}>\pi_{1}^{C M_{1}}$. After insertions from (A4), (A9), and (A10), this condition can be rewritten as

$$
\frac{1}{2} \pi_{123}^{C M}+\pi_{1}^{P O}+\pi_{2}^{S Q}+\frac{1}{2} \pi_{3}^{P I}>\pi_{1}^{S Q}+\pi_{23}^{P O}+\frac{1}{2} \pi_{12}^{P I} .
$$

It follows that firm 1 prefers $C M_{2}$ to $C M_{1}$ when $(k, a) \in C_{2} Y_{C_{1}}^{1}:=\{(k, a) \in Z \mid$ $\left.a>a_{C_{2} C_{1}}^{1}(k)\right\}$, where

$$
a_{C_{2} C_{1}}^{1}(k):=\frac{-3 k^{3}+18 k^{2}+7 k+2+2 \sqrt{-27 k^{5}+102 k^{4}+42 k^{3}+10 k^{2}-11 k+4}}{3(k+1)(1-k) k} .
$$

Other comparisons at node 1 are more straightforward. We find, in the choice between $P I$ and $C M_{2}$, that firm 1 always prefers $C M_{2}$ in the relevant region. Likewise, it always prefers, in the respective relevant regions, $P I$ to $S Q$ and $P O$ to $P I$. See Figure 4 in the text for details. Note in particular that the $C M$ region is split in two by the (A11) curve.

\section{A.4 The four-firm case}

In the main text, only the simplified picture of the merger game is provided, in which the AA nodes, where the AA makes decisions whether to accept proposed mergers, are subsumed. Here, in Figure A4, we provide the full merger game. In two instances, nodes 2 and 6 , a merger node is followed by two different AA nodes, since there are two different mergers available. The two AA nodes in each of the two cases are kept apart by denoting them $2 A$ and $2 B$, respectively $6 A$ and $6 B$. The detailed analysis of this game is in an online appendix.

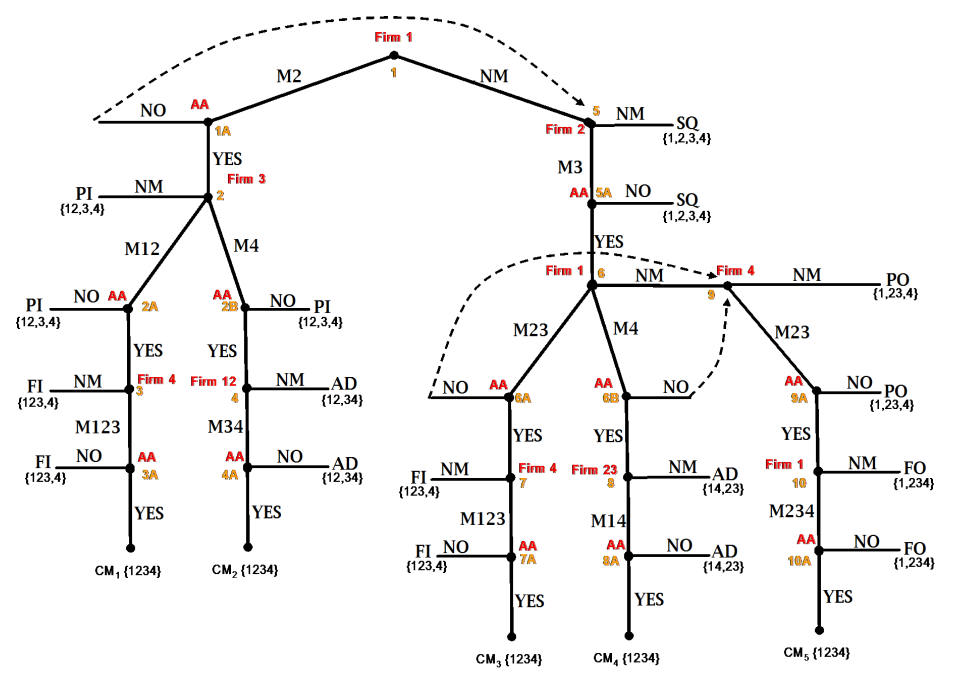

Figure A4. The four-firm merger game. 


\section{A.5 Restricted AA}

In this Section, we provide details of the alternative model with a myopic AA discussed in Section 5.

At node $4 A$, there is no difference between the behavior of a myopic AA and that of a forward looking one. Therefore, also node 4 is not affected by this new assumption.

At node $3 A$, the AA is now comparing $P O$ with the status quo without considering that, for some parameters, the merger game leads to complete monopoly. This myopic AA will accept the merger proposal between firms 2 and 3 if and only if $a<a_{O Q}^{A}(k)$; see (A5). Figure A5 presents the outcomes at node $3 A$. Comparing Figure A5 with Figure A1, one can see that the $S Q$ region now is slightly larger.

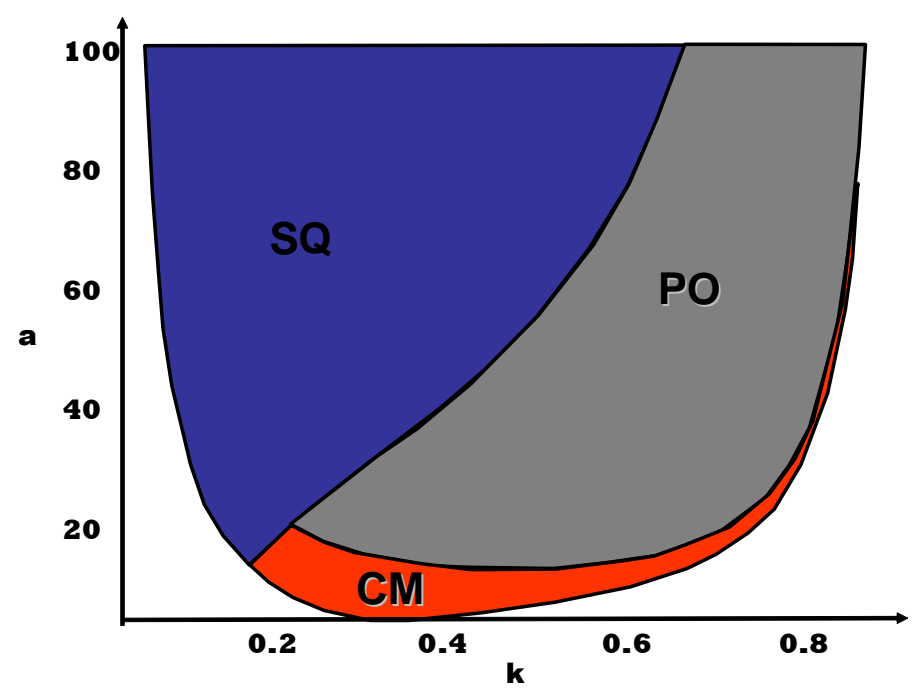

Figure A5. Restricted AA: outcomes at node $3 A$.

At node 3 , firm 2 will propose any merger that will be accepted at node $3 \mathrm{~A}$.

At node $2 A$, as at node $4 A$, there are no changes. Therefore, there are no changes at node 2 as well.

At node $1 A$, the myopic AA makes a comparison only between $P I$ and $S Q$ and accepts the merger proposal between firms 1 and 2 if and only if $a<a_{I Q}^{A}(k)$; see (A7). The outcomes at node $1 A$ are depicted in Figure A6. This graph is dramatically different from Figure A3. The myopic AA accepts this merger proposal more often than a forward-looking AA would do. In particular, there are now cases where firm 1 will have the merger accepted and eventually end up with complete monopoly, even when it is very big.

At node 1, equilibrium behavior is almost never affected by the assumption of the AA being myopic. The only difference occurs for a small parameter region where the firms no longer can obtain complete monopoly merger because 
the AA, at node $3 A$, no longer makes any comparison between $C M$ and $S Q$. Instead, the firms at node 1 have to settle with the $P I$ outcome in this case. This means that the parameter region giving rise to a decision not to merge because of pill sweetening has been slightly reduced.

Changes in the equilibrium outcome, as depicted in Figure 13 in the text, are otherwise not attributable to changes in firms' behavior at node 1 but rather to changes in the AA's behaviour at node $1 A$. In particular, we now have a large region of $C M$ for high values of $k$. As seen in Figure 13, there is also a thin slice of a $P I$ region between $C M$ and $P O$.

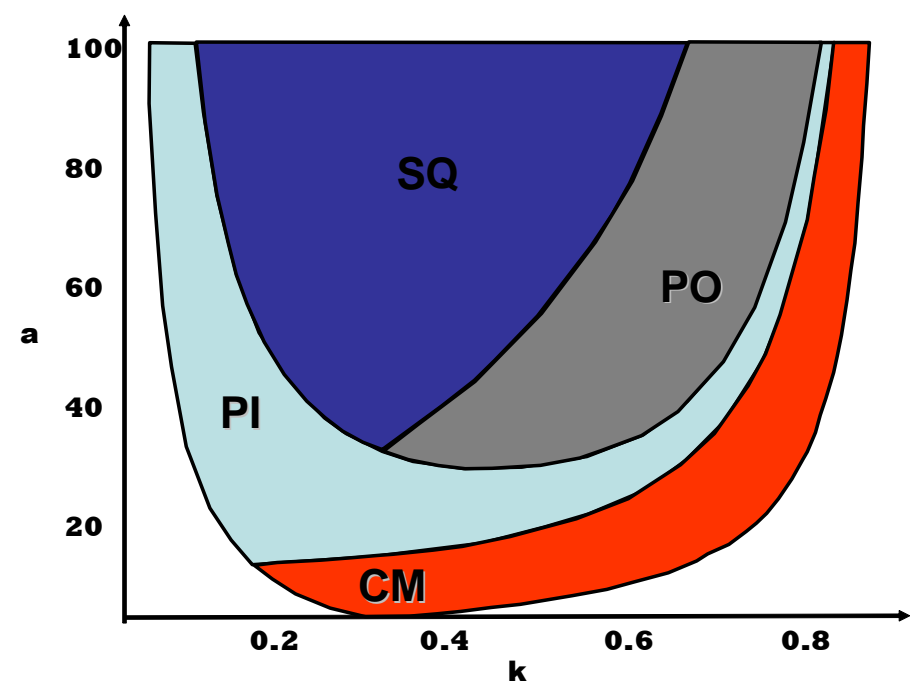

Figure A6. Restricted AA: outcomes at node $1 A$.

\section{References}

[1] Armstrong, M. and J. Vickers, "A Model of Delegated Project Choice", Econometrica 78, 213-244.

[2] Ashenfelter, O., D. Hosken, and M. Weinberg (2014), "Did Robert Bork Understate the Competitive Impact of Mergers? Evidence from Consummated Mergers", Journal of Law and Economics 57, S67-S100.

[3] Barros, P.P. (1998), "Endogenous Mergers and Size Asymmetry of Merger Participants", Economics Letters 60, 113-119.

[4] Blair, R.D. and D.D. Sokol (2012), "The Rule of Reason and the Goals of Antitrust: An Economic Approach", Antitrust Law Journal 78, 471504.

[5] Bloch, F. (1996), "Sequential Formation of Coalitions in Games with Externalities and Fixed Payoff Division", Games and Economic Behavior $14,90-123$. 
[6] Brito, D. (2003) "Preemptive Mergers under Spatial Competition", International Journal of Industrial Organization 21, 1601-1622.

[7] Brito, D. (2005), "Should Alternative Mergers or Acquisitions Be Considered by Antitrust Authorities?", International Journal of Industrial Organization 23, 129-153.

[8] Burguet, R. and R. Caminal (2015), "Bargaining Failures and Merger Policy", International Economic Review 56, 1019-1041.

[9] Carlton, D.W. (2007), "Does Antitrust Need To Be Modernized?", Journal of Economic Perspectives 21(3), 155-176.

[10] Caves, R. E. (1991), "Corporate Mergers in International Economic Integration", European Financial Integration (A. Giovannini and C. Mayer, eds.), Cambridge University Press, pp. 136-160.

[11] Cunha, M. and H. Vasconcelos (2018), "Sequential Mergers and Antitrust Authority's Decisions in Stackelberg Markets", Journal of Industry, Competition, and Trade 18, 373-394.

[12] Farrell, J. and M.L. Katz (2006), "The Economics of Welfare Standards in Antitrust", Competition Policy International 2(2), 3-28.

[13] Farrell, J. and C. Shapiro (1990), "Horizontal Mergers: An Equilibrium Analysis", American Economic Review 80, 107-126.

[14] Fauli-Oller, R. (2000), "Takeover Waves", Journal of Economics and Management Strategy 9, 189-210.

[15] Fridolfsson, S.-O. (2007), "Anti- versus Pro-Competitive Mergers", Working Paper 694, Research Institute of Industrial Economics, Stockholm.

[16] Fridolfsson, S.-O. and J. Stennek (2005a), "Hold-Up of Anti-Competitive Mergers", International Journal of Industrial Organization 23, 753-775.

[17] Fridolfsson, S.-O. and J. Stennek (2005b), "Why Mergers Reduce Profits and Raise Share Prices: A Theory of Preemptive Mergers", Journal of the European Economic Association 3, 1083-1104.

[18] Fumagalli, E. and H. Vasconcelos (2009), "Sequential Cross-Border Mergers", International Journal of Industrial Organization 27, 175-187.

[19] Garcia, F., J.M. Paz y Miño, and G. Torrens (2018), "Collusion, Mergers and Antitrust Policy", unpublished manuscript, Indiana University.

[20] Glick, M. (2018), "The Unsound Theory behind the Consumer (and Total) Welfare Goal in Antitrust", Antitrust Bulletin, forthcoming.

[21] Gowrisankaran, G. (1999), "A Dynamic Model of Endogenous Horizontal Mergers", RAND Journal of Economics 30, 56-83.

[22] Horn, H. and L. Persson (2001a), "Endogenous Mergers in Concentrated Markets", International Journal of Industrial Organization 19, 12131244.

[23] Horn, H. and L. Persson (2001b), "The Equilibrium Ownership of an International Oligopoly", Journal of International Economics 53, 307-333. 
[24] Hovenkamp, H.J. (2019), "Prophylactic Merger Policy", Hastings Law Journal 70, 45-74.

[25] International Competition Network (2011), Competition Enforcement and Consumer Welfare: Setting the Agenda, 10th Annual ICN Conference, The Hague.

[26] Jeziorski, P. (2015), "Empirical Model of Dynamic Merger Enforcement: Choosing Ownership Caps in U.S. Radio", unpublished manuscript, University of California - Berkeley.

[27] Kamien, M.I. and I. Zang (1990), "The Limits of Monopolization through Acquisition", Quarterly Journal of Economics 105, 465-499.

[28] Kamien, M. I. and I. Zang (1993), "Monopolization by Sequential Acquisition", Journal of Law, Economics and Organization 9, 205-229.

[29] Kaplow, L. (2012), "On the Choice of Welfare Standards in Competition Law", in The Goals of Competition Law (D. Zimmer, ed.), Edward Elgar, pp. 3-26.

[30] Kwoka, J. (2015), Mergers, Merger Control, and Remedies: A Retrospective Analysis of U.S. Policy, MIT Press.

[31] Lyons, B.R. (2003), "Could Politicians Be More Right Than Economists? A Theory of Merger Standards", Working Paper 2003/14, Robert Schuman Centre for Advanced Studies, European University Institute, Florence.

[32] Macho-Stadler, I., D. Pérez-Castrillo, and N. Porteiro (2006), "Sequential Formation of Coalitions through Bilateral Agreements in a Cournot Setting", International Journal of Game Theory 34, 207-228.

[33] Mermelstein, B., V. Nocke, M.A. Satterthwaite, and M.D. Whinston (2018), "Internal versus External Growth in Industries with Scale Economies: A Computational Model of Optimal Merger Policy", Journal of Political Economy, forthcoming.

[34] Motta, M. (2004), Competition Policy: Theory and Practice, Cambridge University Press.

[35] Motta, M. and H. Vasconcelos (2005), "Efficiency Gains and Myopic Antitrust Authority in a Dynamic Merger Game", International Journal of Industrial Organization 23, 777-801.

[36] Neary, J.P. (2007), "Cross-Border Mergers as Instruments of Comparative Advantage", Review of Economic Studies 74, 1229-1257.

[37] Nilssen, T. (1997), "On the Consistency of Merger Policy", Journal of Industrial Economics 45, 89-100.

[38] Nilssen, T. and L. Sørgard (1998), "Sequential Horizontal Mergers", European Economic Review 42, 1683-1702.

[39] Nocke, V. and M.D. Whinston (2010), "Dynamic Merger Review", Journal of Political Economy 118, 1200-1251. 
[40] Nocke, V. and M.D. Whinston (2013), "Merger Policy with Merger Choice", American Economic Review 103, 1006-1033.

[41] Qiu, L.D. and W. Zhou (2007), "Merger Waves: A Model of Endogenous Mergers", RAND Journal of Economics 38, 214-226.

[42] Perry, M. and R.H. Porter (1985), "Oligopoly and the Incentive for Horizontal Merger", American Economic Review 75, 219-227.

[43] Pesendorfer, M. (2005), "Mergers under Entry", RAND Journal of Economics 36, 661-679.

[44] Ray, D. and R. Vohra (1999), "A Theory of Endogenous Coalition Structures", Games and Economic Behavior 26, 286-336.

[45] Rodrigues, V. (2014), "Restructuring and Merger Waves", International Journal of Economic Theory 10, 355-369.

[46] Ross, T.W. and R.A. Winter (2005), "The Efficiency Defense in Merger Law: Economic Foundations and Recent Canadian Developments", $A n$ titrust Law Journal 72, 471-503.

[47] Salant, S., S. Switzer, and R. Reynolds (1983), "Losses Due to Merger: The Effects of an Exogenous Change in Industry Structure on Cournot-Nash Equilibrium", Quarterly Journal of Economics 98, 185-199.

[48] Salvo, A. (2010), "Sequential Cross-Border Mergers in Models of Oligopoly", Economica 77, 352-383.

[49] Seldeslachts, J., J.A. Clougherty, and P.P. Barros (2009), "Settle for Now but Block for Tomorrow: The Deterrence Effects of Merger Policy Tools", Journal of Law and Economics 52, 607-634.

[50] Stigler, G.J. (1950), "Monopoly and Oligopoly by Merger", American Economic Review Papers and Proceedings 40, 23-34.

[51] Tombak, M.M. (2002), "Mergers to Monopoly", Journal of Economics and Management Strategy 11, 513-546.

[52] Vasconcelos, H. (2005), "Tacit Collusion, Cost Asymmetries, and Mergers", RAND Journal of Economics 36, 39-62.

[53] Whinston, M.D. (2007), "Antitrust Policy toward Horizontal Mergers", in Handbook of Industrial Organization, vol. 3 (M. Armstrong and R. Porter, eds.), Elsevier, pp. 2369-2440. 